Schulich School of Law, Dalhousie University

Schulich Law Scholars

Research Papers, Working Papers, Conference

Papers

Faculty Scholarship

6-29-2013

\title{
When Everyone is an Orphan: Against Adopting a US-Styled Orphan Drug Policy in Canada
}

Matthew Herder

Dalhousie University, matthew.herder@dal.ca

Follow this and additional works at: https://digitalcommons.schulichlaw.dal.ca/working_papers

Part of the Health Law and Policy Commons

\section{Recommended Citation}

Matthew Herder, "When Everyone is an Orphan: Against Adopting a US-Styled Orphan Drug Policy in Canada" (2013) Dalhousie University Schulich School of Law Working Paper No 46.

This Working Paper is brought to you for free and open access by the Faculty Scholarship at Schulich Law Scholars. It has been accepted for inclusion in Research Papers, Working Papers, Conference Papers by an authorized administrator of Schulich Law Scholars. For more information, please contact hannah.steeves@dal.ca. 


\title{
When Everyone is an Orphan: Against Adopting a US-styled Orphan Drug Policy in Canada*
}

\author{
*This is a preprint of an article whose final and definitive form has been published in \\ Accountability in Research 2013 (copyright Taylor \& Francis); \\ Accountability in Research is available online at: \\ http://www.tandfonline.com/doi/full/10.1080/08989621.2013.793120\#.Uc28FetQ3uY
}

Matthew Herder, BSc (hons.), LL.B., LL.M., J.S.M. Assistant Professor, Health Law Institute

Faculties of Medicine and Law, Dalhousie University

\begin{abstract}
: 150 words
Putting aside whether diseases that affect only small numbers of people ("rare diseases") should be prioritized over diseases that are otherwise orphaned, in this paper I argue that a new approach to rare, orphan diseases is needed. The current model, first signaled by the United States' Orphan Drug Act and subsequently emulated by several other jurisdictions, relies on a set of open-ended criteria and market-based incentives in order to define and encourage drug therapies for rare, orphan diseases. Given a) the biopharmaceutical industries' growing interest in orphan diseases, b) progress in the sphere of personalized medicines enabling more and more common diseases to be reclassified as rare, and c) empirical evidence suggesting that the most orphan drugs target only a limited, lucrative subset of rare diseases, I argue that Canada, which recently announced plans to develop its own "orphan drug framework" should not follow the United States' orphan drug model.
\end{abstract}

Acknowledgement: This paper benefited from comments from several scholars and researchers, including Françoise Baylis, Conrad Fernandez, Michael Taylor, and the members of the Novel Tech Ethics group at Dalhousie University. I am also indebted to the members of the Genome Canada-funded "IGNITE" project led by Christopher McMaster and Conrad Fernandez for cultivating my interest in policy issues surrounding rare diseases. As well, Health Canada's input and in-kind involvement in IGNITE significantly informed my research and analysis. Finally, I would like to thank two reviewers for their comments and suggestions, which strengthened the final version of this paper considerably. 
Public policy seldom anticipates the challenges that scientific or economic developments present to society. However, recent progress toward more "personalized medicines" coupled with newly announced plans for a Canadian "orphan drug framework" (Health Canada 2012a) offer a rare moment for proactive policy thinking. In this paper I argue that Canada is today in a fundamentally different position than the United States (1983), Japan (1993), Australia (1997), or even Europe (2000) was, when each enacted orphan drug laws. The effects of those laws are now becoming evident, meanwhile the pharmaceutical and biotechnology industries have changed significantly, and there is an abundance of findings from genomics, epigenomics, and related "omics" fields that are, to varying degrees, being incorporated into drug development platforms. Together, these factors should motivate Canada to depart from the United States' led model of incentivizing orphan disease research and drug development.

The current policy model for orphan drugs defers to the marketplace for judgment as to which orphan diseases to focus upon in research and therapeutic development. I argue here that Canada's publicly funded researchers, research institutions, research funding agencies, and—ultimately—Canada's publics should instead take up the business of choosing amongst orphaned diseases.

The core insight driving the paper's argument is that the very idea of an orphan disease has always been—and will increasingly be-up for grabs. This insight is not new. In his chapter in the 1986 book Orphan diseases and orphan drugs Kenneth Warren of 
the Rockefeller Foundation put the point plainly: "the category of orphan diseases bears no essential relationship to their prevalence, morbidity or mortality." (Warren 1986, 170) A variety of factors can, rather, occasion neglect along a continuum of knowledge inquiry, from medical education to private sector research and drug development programs. Upstream, diseases may be orphaned by their own perceived banality. According to Warren, medical education tends to downplay "the usual, the uninteresting and the non-lethal," for instance, leading those in paediatric training to "focus on relatively rare genetic diseases rather than the 'common' cold and croup, and in adult medicine on heart disease and cancer rather than arthritis and alcoholism." (Warren 1986, 169) Downstream, market forces can orphan diseases, either because they afflict those with little purchasing power (so-called "tropical diseases" or "neglected diseases"), (Trouiller et al. 2001) or, because they affect so few in number (so-called "rare diseases") such that the costs of therapeutic development are predicted to exceed product revenues. In public policy parlance orphan disease has become synonymous with such rare diseases. But even within this subset of orphans, there is growing heterogeneity. Arti Rai and others have pointed out for over a decade that better understanding of the molecular correlates of disease promises to transform diseases that are currently common in the population into new sub-categories of rare disease in a population. (Rai 2001; Loughnot 2005; Maher and Haffner 2006) The collapsing space between upstream research inquiry and downstream resource allocations by biopharmaceutical firms is hastening the discovery of new classifications of disease, many of which will fit into population-based definitions of orphan (read: rare) disease. 
In this paper I argue that the increasing number of, and diversity of interests bound up in, (Huyard 2009) orphan diseases seriously complicates the purpose of any orphan drug policy even if we agree that the term orphan should be read as meaning rare. The substance of the United States' Orphan Drug Act (1983) approach to orphan drugs, subsequently emulated by other jurisdictions, is to fashion incentives so as to encourage drug manufacturers to do that which small populations of patients would apparently not otherwise encourage them to do. These laws and the incentives they confer do not discriminate between older and newer rare diseases, i.e., diseases that-following findings in 'omics related sciences-are re-characterized as rare. In the abstract, it is not clear that they should distinguish the two. Why should orphan drug policies prioritize drug development for rare diseases that currently lack any treatment options ahead of drug development for sub-divisions of common diseases with treatment options of limited efficacy? In reality, the task of discriminating amongst rare diseases, of selecting which therapies ought to receive added encouragement from the state, will become both increasingly important yet increasingly vexed. The biopharmaceutical industries are moving more and more in the direction of rare diseases (in 2009 and 2010 roughly a third of all drug approvals granted by the Food and Drug Administration in the United States carried an orphan designation (Coté et al. 2010a; Wellman-Labadie and Zhou 2010)), and progress toward more targeted therapies is introducing more diseases into the realm of the rare. The orphan drug criteria and market-based incentives that orphan drug laws employ will not do the work of discriminating amongst the growing number of rare 
diseases and may contribute to other problems, most notably, rising healthcare costs. A different approach to orphan diseases and drugs is therefore needed.

The paper's analysis has two chief limits. First, I do not directly engage with the question of whether rare diseases of the North should be prioritized, through governmental policy, ahead of neglected diseases of the South. Canada has an "access to medicine regime" to address the latter already on the books. It was supposed to facilitate generic drug manufacturers' production of anti-retroviral drugs to treat HIV/AIDS and other essential medicines for designated developing countries. But the law is widely regarded as a failure due to the long and complicated process that developing countries and generic manufacturers must follow before essential medicines can be made available. (Elliott 2007) Only one shipment of such essential medicines to a developing country has occurred to date, and repeated attempts to redress its shortcomings have been thwarted by the present federal government. (Galloway 2012; Anon. 2012) At the same time, the federal government is moving ahead with an orphan drug framework for rare diseases. (Health Canada 2012a) The prioritization embedded in this policy choice ought to be critically examined but is beyond the scope of this work. The analysis here is limited to orphan diseases that are rare.

Second, while I argue here that ethical considerations and the perspectives of Canadian publics should be integrated into the process of choosing amongst rare, orphaned diseases, I do not take a position on precisely how this should occur except in one important regard; namely, timing. The literature to date on rare disease drug 
therapies, (Drummond et al. 2007; Drummond et al. 2009) or biopharmaceuticals more generally, (Flood and Dyke 2012) acknowledges there is a fundamental disconnect between the standards of safety and efficacy applied at the regulatory stage of market authorization and the thresholds of cost-effectiveness typically required by healthcare payers at the stage of reimbursement. Commentators have thus asked, "why have incentives to develop such drugs if they will later be judged by criteria on which they are doomed to fail?" (Drummond et al. 2007, p. 38) But the move that almost all of these commentators make in response to this disconnect is to propose changes to the reimbursement stage, by building opportunities for public participation in healthcare coverage decisions, using other ethical, value-based criteria (e.g., equity) in addition to cost-effectiveness measures, and/or introducing more flexible outcomes (e.g., coverage with evidence development). (Panju and Bell 2010; Menon and Stafinski 2008; Menon and Stafinski 2011; Menon et al. 2011; Drummon et al. 2007; Drummond et al. 2009; Winquist et al. 2012) None imagine an enhanced role for publics and/or value-based criteria at the regulatory stage. I do that here in view of the growing heterogeneity of rare, orphan diseases and on the strength of the assumption that integrating ethical, value-type considerations and some level of public participation into innovation design processes will, over time, precipitate better healthcare options (Lehoux et al. 2008) and/or help legitimize, in a democratic sense, inexorably difficult resource allocation decisions in healthcare. ${ }^{1}$ (Daniels 2000; Daniels and Sabin 1997) How precisely Canadian publics should be involved, and what criteria should be added to mix is, again, critical but largely beyond the scope of the present work. I limit my task to unpacking the potential

\footnotetext{
${ }^{1}$ Defending this assumption is beyond the scope of this article.
} 
advantages and disadvantages of three policy models (a modified "Health Impact Fund," a "grant-and-access pathway," and publicly funded clinical trials)—any one of which will widen the kinds of considerations and sources of input relative to the US orphan drug model—to stage further policy discussion.

The outline of the paper is as follows. In Section I, I explain the United States' orphan drug model, minor variations to the model made in other jurisdictions, and Canada's policy inaction to date. In Section II, I present the argument against adopting the United States' model in Canada given a) relevant changes in the biotech and pharmaceutical industries, b) recent progress in the sphere of "personalized medicines", and c) empirical evidence about the impact of the United States' model upon patterns of research and development. In Section III, I analyze two sets of policy options, advocating in favour of those that seek to integrate ethical considerations and input from Canadian publics given the shifting and heterogeneous nature of orphan diseases. In conclusion, Section IV calls upon policy-makers to develop an alternative orphan drug policy mechanism for rare diseases, or else risk orphaning (read: neglecting) many more Canadians in the future.

\section{Orphan Drugs for Rare Diseases: A Common Approach}

Henry Waxman, a longstanding member of the United States (US) House of Representatives whose orphan drug bill became law in 1983, begins his history of the US' Orphan Drug Act with a story: 
In March 1980 a constituent of mine in Los Angeles called to tell me that her son's physician had just returned from Canada with a six-month supply of a drug called Pimozide. While the drug was approved in Canada, it had been confiscated at the Los Angeles airport because it was not approved in the United States. The mother said to me, 'Mr. Waxman, my son has Tourette syndrome and I have only eight days of Pimozide left for him. What are you going to do about it?

Unfortunately, there was little that could be done for her that day. But I soon began a series of Congressional hearings at which the young man, Adam Seligman, and other courageous individuals with rare diseases opened their lives to the American people in hopes that the public and the Congress would understand and help.

During the initial hearing in June 1980, it became apparent that while there was much interest in drugs for rare diseases, there was no consensus on the scope of the problem or what should be done. Many witnesses talked of broader problems. They described orphan medical devices and medically necessary foods that needed incentives for development. They spoke of drugs for the less developed countries of the world and vaccines which were orphans as much as were drugs for rare diseases.

$[\ldots]$

Soon after the hearing I decided that, because of the lack of consensus, we should restrict our efforts to drugs for disease that are rare in the United States. Even though the drug manufacturers claimed that product liability concerns could force them out of the vaccine business and that they had little incentive to develop drugs for diseases indigenous to the less developed countries, these related problems could have jeopardised any effort to focus on rare diseases in the United States. A tough practical decision of legislative politics had to be made. (Waxman 1986, 136-37)

This story is remarkable on several levels. Given the current interest in developing a Canadian orphan drug framework, Waxman's story has an element of irony: the availability of a particular drug in Canada in 1980 inspired Waxman's interest in rare diseases, culminating in the very Orphan Drug Act that Canada is now poised to copy. The story also underscores how amorphous the concept of an orphan disease can be. Waxman made a calculated decision to narrow the "scope of the problem" to rare diseases. Other problems, including neglected diseases of the South, were on the table but Waxman chose to limit the legislation's focus by the time his bill was introduced in late 
1981. Since the law was enacted in 1983, a handful of medications intended to address neglected diseases have secured orphan designations and, later, regulatory approval in the US and elsewhere. (Kesselheim 2011, p. 468; Haffner et al. 2008; Lang et al. 2005) But, as I explain below, orphan diseases have become synonymous with rare diseases, in part, because other jurisdictions have made essentially the same choices as Representative Waxman in terms of defining the "scope of the problem" and in terms of the incentive mechanisms that they have crafted to try and correct it.

In this section of the paper I distil the four key choices of legislators in the US, subsequently followed by law-makers in Japan, Australia, and the European Union (EU), to describe what I call the US orphan drug model. These are not the only jurisdictions with orphan drug policies in place. Since 1993 nearly a dozen other countries, concentrated in Southeast Asia, have reportedly enacted US-styled orphan drug laws, regulations, or administrative policies. (Sharma et al. 2010) For practical reasons, ${ }^{2}$ though, I focus here on the US, Japan, Australia, and the EU.

My objective in this section is not to present a detailed historical account of the orphan drug policies in these four jurisdictions although the work of patient organizations behind the scenes is an interesting common thread. (Waxman 1986; Huyard 2009; Dunkle et al. 2010) Comparisons of the four policies are readily available in the literature. (Thamer et al. 1998; Cheung et al. 2004; Rinaldi 2005; Panju and Bell 2010;

\footnotetext{
${ }^{2}$ I focus on the laws and policies of the US, Japan, Australia, and the European Union because those instruments are, unlike the laws and policies of other jurisdictions, readily available in English or summarized in detail in the literature.
} 
Sharma et al. 2010) Rather, my objective is to show that the US orphan drug model is as open-ended as it is market-oriented. It uncritically accepts that treatments for rare diseases will—as a rule—not be commercially viable to develop, allows manufacturers to obtain multiple orphan designations for the same drug and dictate the boundaries of (rare) disease, defers to their judgment as to which orphan diseases ought to be pursued in research and drug development, and creates a variety of market-based incentives in support of the same. This leads to an ever-increasing window for designating drugs as orphan products, paired with increasing market protections for those that gain regulatory approval.

The first two subsections below map onto the two primary elements of the US model: a) a set of criteria for defining orphan disease; and, b) a package of incentives to encourage orphan disease research and orphan drug development. Subsection c) works as a transition to the argument in Section II of the paper against Canada adopting the US orphan drug model in spite of recent recommendations from a Parliamentary Committee to that effect. (Standing Senate Committee on Social Affairs, Science and Technology 2012)

\section{a) Defining Orphan Disease}

Regulators in the US, Japan, Australia, and Europe apply multiple criteria in determining whether a given product qualifies for an orphan designation. In this subsection I explain how the eligibility criteria in the US orphan drug law became less 
stringent shortly after its enactment, and describe the generous ways in which US regulators have chosen to interpret the terms "same drug" and "disease."

\section{i. Accepting that Orphan Drugs are Not Commercially Viable}

Orphan diseases tend to be described in terms of the total number of people with a given condition (e.g. $\leq 50,000$ people in Japan), or its incidence (e.g. $\leq 5$ cases per 10,000 people across EU states), within a population. Each of the four jurisdictions of interest here have set slightly different prevalence- or incidence-based thresholds for an orphan disease, ranging from an incidence of approximately $0.01 \%$ of the population in Australia to $0.07 \%$ of the population in the US. (Panju and Bell 2010) However, with the exception of Japan where prevalence in concert with other criteria noted below determines orphan eligibility, the US, Australia, and EU all allow, in principle, drugs for larger populations to qualify for orphan designations.

Originally, the US law defined orphan diseases solely as diseases "for which there is no reasonable expectation that the cost of developing and making available in the United States a drug for such disease or condition will be recovered from sales in the United States of such drug." (Orphan Drug Act 1983) There was no set prevalence threshold for orphan diseases; rather, manufacturers were to satisfy the foregoing commercial viability test in order to gain the market advantages conferred by the legislation. Industry, however, expressed concern that such a standard would applied in an unpredictable manner. (Loughnot 2005, p. 375) So in 1984, less than a year after the Orphan Drug Act was passed, the simpler prevalence-based definition was added to the 
law: any drug that targeted a condition affecting no more than 200,000 people in the US could be designated as an orphan drug. ${ }^{3}$ (Waxman 1986, pp. 144-145)

The commercial viability test remained part of the US' legislation and similar language was incorporated into Australia's Therapeutic Goods Regulations (1997) as well as the EU's Regulation on Orphan Medical Products (EC 2000a; EC 2000b). Thus, provided the anticipated sales would not cover the costs of research and development, ${ }^{4}$ drugs targeting conditions that affect larger groups of people can, in theory, qualify as orphan drugs in those three jurisdictions. (See Table 1) However, exceedingly few orphan drug designations have been sought under this alternative criterion, (Kesselheim 2011) presumably, because it would open manufacturers up to an audit of their actual research and development costs-information that manufacturers carefully guard as confidential. (Light and Warburton 2011, p. 35)

Table 1. Orphan Drug Criteria in the US, Japan, Australia, and European Union.

\begin{tabular}{l|llll}
\hline Criterion & United States & Japan & Australia & Europe \\
\hline Prevalence- or & $\leq 200,000$ & $\leq 50,000$ & $\leq 2,000$ & $\leq 5$ per 10,000 \\
Incidence- & & & & \\
Based & & & & \\
Threshold & & & \\
\hline
\end{tabular}

${ }^{3}$ This figure was "arbitrarily determined by the observation that companies were unwilling to manufacture drugs for narcolepsy or multiple sclerosis, each believed to affect approximately 200,000 persons." (Arno et al. 1995, p. 234) We now know that the number of persons in the US with narcolepsy and multiple sclerosis is far lower and higher, respectively, than this 200,000 figure, yet it remains unchanged.

${ }^{4}$ Note that only the EU seems to require that the disease or condition be one that affects people within the jurisdiction; according to the wording of the legislation in the US and Australia it is open to manufacturers to develop a product for peoples elsewhere provided sales in the US or Australia would not cover the research and development costs. 


\begin{tabular}{|c|c|c|c|c|}
\hline Criterion & United States & Japan & Australia & Europe \\
\hline $\begin{array}{l}\text { Alternative } \\
\text { Commercial } \\
\text { Viability Test }\end{array}$ & $\begin{array}{l}\text { "No reasonable } \\
\text { expectation" of } \\
\text { recovering } \\
\text { costs through } \\
\text { sales in the } \\
\text { United States }\end{array}$ & NA & $\begin{array}{l}\text { "Not } \\
\text { commercially } \\
\text { viable to supply } \\
\text { to treat, prevent } \\
\text { or diagnose } \\
\text { another disease } \\
\text { or condition" }\end{array}$ & $\begin{array}{l}\text { "Unlikely that } \\
\text { the marketing } \\
\text { of the } \\
\text { medicinal } \\
\text { product in the } \\
\text { Community } \\
\text { would generate } \\
\text { sufficient return } \\
\text { to justify the } \\
\text { necessary } \\
\text { investment" }\end{array}$ \\
\hline $\begin{array}{l}\text { Seriousness of } \\
\text { the Disease }\end{array}$ & $\mathrm{NA}(2)$ & NA & $\mathrm{NA}(2)$ & $\begin{array}{l}\text { Must address a } \\
\text { "life- } \\
\text { threatening or } \\
\text { chronically } \\
\text { debilitating } \\
\text { condition" } \\
\text { (under the } \\
\text { population } \\
\text { standard) or } \\
\text { address a "life- } \\
\text { threatening, } \\
\text { seriously } \\
\text { debilitating or } \\
\text { serious and } \\
\text { chronic } \\
\text { condition in the } \\
\text { Community" } \\
\text { (under the } \\
\text { commercial } \\
\text { viability test) }\end{array}$ \\
\hline Unmet need & $\mathrm{NA}(3)$ & $\begin{array}{l}\text { "High medical } \\
\text { need"'(4) }\end{array}$ & NA & $\begin{array}{l}\text { "No } \\
\text { satisfactory } \\
\text { method of } \\
\text { diagnosis, } \\
\text { prevention or } \\
\text { treatment of the } \\
\text { condition in } \\
\text { question that } \\
\text { has been } \\
\text { authorized in } \\
\text { the Community }\end{array}$ \\
\hline
\end{tabular}




\begin{tabular}{|c|c|c|c|}
\hline Criterion & United States & Japan Australia & Europe \\
\hline & & & $\begin{array}{l}\text { or, if such } \\
\text { method exists, } \\
\text { that the } \\
\text { medicinal } \\
\text { product will be } \\
\text { of significant } \\
\text { benefit to those } \\
\text { affected by that } \\
\text { condition" }\end{array}$ \\
\hline
\end{tabular}

Notes: (1) "NA" means 'not applicable'. (2) While the US and Australia do not require a drug to target a particularly serious disease or condition to be eligible for orphan drug status, the benefit of "fast-tracking" (discussed in Section I(b) below) is only available in such instances. (3) The US does not require that orphan drugs address a disease for which there is no treatment or that they constitute a marked improvement in safety and efficacy compared to existing treatments. But it holds applications to that standard indirectly by precluding multiple orphan drugs for the same indication unless they are shown to be of improved safety and/or efficacy. (Loughnot 2005) (4) This criterion means "either there is no alternative drug... or it is expected to have much higher efficacy or safety compared to the existing drugs and other treatment." (Narukawa 2001; Thamer et al. 1998)

Another criterion originally included in the US' Orphan Drug Act concerned the "patentability" of purported orphan drugs. Studies completed by Congressional Committees while the law was in development suggested that drugs used to treat rare diseases were seldom patented. This de facto absence of patent rights helped to justify the inclusion of a seven-year period of "market exclusivity" in the statute. Congress, in turn, initially conditioned orphan drug status - and access to specially created incentives like market exclusivity—on the non-patentability of a given product. (Waxman 1986, pp.

\footnotetext{
${ }^{5}$ This form of market protection will be explained in depth below and differentiated from patent rights as well as other types of exclusivity available to orphan drugs.
} 
However, the de facto absence of patents on the orphan-like products surveyed by Congress prior to the law's enactment does not equate with the de jure non-patentability of products tendered as orphan drugs post 1983. Companies complained that establishing non-patentability was, like the commercial viability test, unworkable. And, in 1985, the Orphan Drug Act was amended again, dropping the requirement of non-patentability altogether. (Waxman 1986, p. 145; Loughnot 2005, pp. 369-370) Japan, Australian, and the EU did not subsequently entertain any sort of non-patentability requirement for orphan drug designation. Today, most orphan products on the market appear to enjoy some, if not multiple forms, of patent protection as well as a multi-year period of market exclusivity. (Rogoyski 2006)

These two choices by US legislators evidence a move away from a system that tested the commercial viability of an alleged orphan product—by requiring manufacturers to satisfy the commercial viability test and show non-patentability—to a system that assumed products were not commercially viable provided they were aimed at sufficiently small populations. By relying on a prevalence-based criterion (Japan), or coupling prevalence- or incidence-based standards befitting their own regions (Australia and the EU) with what have become token tests of commercial viability, while remaining silent on the issue of patentability, the three other jurisdictions have endorsed the same assumption; namely, that a product will not be commercially viable to develop if it targets a rare disease.

\section{ii. Generous Interpretations of "Same Drug" and "Disease"}


Since the Orphan Drug Act's inception the FDA has followed a policy of "not consider[ing] requests for [the same] orphan drug designation made after that drug has received full FDA marketing approval for that particular disease." (FDA 1986) Conversely, a single drug can receive multiple orphan designations provided each corresponds to a different medical indication.

In the past, applying this policy was relatively straightforward. Deciphering whether a given drug was the "same" was a simple, chemistry-based assessment. (Bohrer and Prince, p. 384; Loughnot 2005, p. 376) Increasingly, though, companies are attempting to bring more complex, biologic products to market. This led the FDA to abandon any evaluation of "sameness," choosing instead to "equate 'different' with “clinically superior"' in 1992. (Loughnot 2005, p. 376; Orphan Drug Regulations 1992) Other jurisdictions have, in effect, adopted the same policy by requiring either that no medications exist for the condition in question or, in the event that they do, that any new orphan drug candidate mark a demonstrable improvement. Japan, for instance, stipulates that the disease in question is regarded as a "high medical need," (Thamer et al. 1998) which has been defined by its regulator to mean "either there is no alternative drug and other treatment or it is expected to have much higher efficacy or safety compared to the existing drugs and other treatment." (Narukawa 2001) Likewise, the EU limits orphan status to products targeting diseases for which there exists "no satisfactory method of diagnosis, prevention or treatment of the condition in question...or, if such method exists, 
that the medicinal product will be of significant benefit to those affected by that

condition." (See Table 1 above)

In this way, the US orphan drug model opens a space for manufacturers to seek multiple orphan drug designations for the same drug. Demonstrations of clinical superiority are ordinarily welcome. ${ }^{6}$ But clinical superiority can be shown, not just by comparing one intervention against another, but also by changing the eligibility criteria for patient inclusion in a clinical trial based on patients' genomic profiles. David Loughnot (2005, p. 376) explains:

[P]harmacogenomics can help identify patients who are susceptible to adverse drug reactions. With such technology, a drug sponsor could create significantly better clinical results without altering a drug at all. Using data gathered during the first clinical trials and subsequent data gathered from market usage, companies could identify genetic subgroups of the population who present a higher likelihood of negative or neutral drug reactions. Then a company could use that information to design a new clinical trial excluding patients who are likely to produce the unwanted results. Thus, the data obtained from this new clinical trial would likely appear more favorable or impressive than the original trial even if both trials used the exact same drug.

\footnotetext{
${ }^{6}$ Commentators argue that the use of placebos in randomized clinical trials is unethical when there is an existing treatment for a condition. However, regulators in Canada and elsewhere have failed to make this a binding requirement, moreover, research ethics guidelines do not capture all clinical trials and may be poorly enforced. (Flood and Dyke 2012) In contrast, many rare diseases lack any treatment options at present. Arguably, this problem of inappropriate use of placebo control groups does not apply. However, as explained in Section II below, the possibility of transforming common conditions into rare ones is increasing. This may in effect define away concerns about inappropriate use of placebos in clinical trials by making it appear that no treatments currently exist for a given rare disease when, in fact, one or more treatments may be available to a wider group of patients, to which members of this newly created type of rare disease previously belonged.
} 
Given industry's growing interest in biologics as well as genomic and epigenomic data (discussed in Section II below), the decision to equate 'difference' with 'clinically superior' is likely to become an increasingly useful feature of the US orphan drug model in the future. Identifying, with greater precision, which patients are most likely to benefit from (or not be harmed by) a drug therapy is obviously important. Whether each and every such targeted therapy should be eligible for an orphan drug designation raises other considerations, however, which I delve into in Sections II and III of the paper.

Shifting trends in biopharmaceutical sectors of industry also underscore the absence of a distinction in the US orphan drug model between rare diseases that have long been identified as such from those which have been reclassified as rare by virtue of new scientific insights. The only relevant constraint adopted by the FDA is that the disease in question be considered "medically plausible," which, in 1992, Congress refused to define with examples despite the ambiguity of the phrase. (Orphan Drug Regulations 1992) Reasoning that applying "the concept [of medically plausible] is a matter of judgment based on the specific facts of each case," Congress preferred to preserve a flexible, case-by-case approach. (Orphan Drug Regulations 1992; Loughnot 2005)

More recently, in a set of proposed rules the FDA acknowledged that the term has precipitated "the creation of subsets of non-rare diseases or conditions that are artificially narrow" and attempted to provide further guidance on this issue. (FDA 2011) But these proposed rules have yet to become binding policy so the list of rare diseases remains 
open to newcomers provided there is a medical basis for the putative orphan. The EU has taken a similar stance, (Michaux 2010) and there is no indication that Japan or Australia has adopted a more stringent standard.

In summary, in terms of the criteria for orphan drug designation, there are four significant choices embedded in the current US model. ${ }^{7}$ The first two choices concern the commercial viability of the alleged orphan product. In contrast to the US' Orphan Drug Act as initially passed, the US orphan drug model does not test a given product's commercial viability; rather, it assumes it is lacking if it is aimed at a patient population of a certain size. Similarly, the model does not require that the product in question be patent-free; rather, it assumes that the product merits market protections in addition to any protections that are otherwise available, again, provided it is aimed at a patient population of a certain size. The third and fourth choices are terminology-related. Specifically, the US orphan drug model flexibly interprets the terms "same drug" and "disease," thereby creating spaces for manufacturers to seek additional orphan drug designations for drugs that already enjoy the benefits of orphan drug status and to game the boundary between common and rare diseases. In the next subsection I detail why manufacturers are wont to take advantage of these open-ended, flexible criteria.

\section{b) Incentivizing Orphan Drugs}

\footnotetext{
${ }^{7}$ There are other criteria incorporated into the orphan drug laws of Japan, Australia, and the EU, but none sets these jurisdictions meaningfully apart from the US model. Perhaps the only exception to this is Japan's stipulation that the therapeutic product tendered as an orphan drug has a "high possibility of [successful] development." (Thamer et al. 1998; Narukawa 2001)
} 
The package of incentives on offer for orphan drug developers varies across the four jurisdictions but the precedent-setting effect of the US model is again plain. There are five types of incentives contained in the US orphan drug model, including tax credits, priority reviews (i.e., "fast-tracking"), research grants or other forms of subsidizing (e.g., regulatory fee waivers), protocol assistance, and market exclusivity. All five of these incentives have been picked up by two, if not all three, of the jurisdictions that followed the US' lead. For example, in the US manufacturers of orphan drugs can receive a tax credit for up to $50 \%$ of the costs incurred during the clinical trial process, which can translate into millions in savings. (Loughnot 2005, p. 369; Valverde et al. 2012) Japan and the EU (through its member states) provide tax credits as well, albeit for lesser amounts (e.g. Japan's tax credit is capped at 12\% (Japan 2009)), leaving Australia as the lone jurisdiction without such an incentive in place. (Panju and Bell 2010) The US' Orphan Drug Act created a grants program that has handed out approximately $\$ 14$ million in research funding per year across tens of projects. (Valverde et al. 2012) Japan has implemented a similar grant program (Japan 2009) and, while not included within the EU's orphan drug regulation itself, national research funding entities in Europe appear to be allocating increasing amounts of funding to research focused on rare diseases. (Gupta 2012; cf. Reinecke et al. 2011) Calls to do the same in Australia have been made recently. (Kirby 2012) All four jurisdictions allow for "fast-tracking" of orphan drug applications provided they target life-threatening or seriously debilitating conditions, ${ }^{8}$ and all four

\footnotetext{
${ }^{8}$ Although this incentive measure is often described as a feature of a given country's orphan drug law, (e.g., Panju and Bell 2010) it is typically available to any drug (orphan
} 
jurisdictions provide "protocol assistance" from the regulator in order to help manufacturers design research protocols for small patient populations that will satisfy standards of safety and efficacy.

These four incentives are critical, particularly the promise of protocol assistance given the difficulty of designing trials for small populations. They save manufacturers substantial amounts of time and money relative to traditional drug development and regulatory pathways. (Meekings et al. 2012) The relationship between orphan drug manufacturers and regulators has thus been described as far more "collegial" compared to other therapeutic products. (Loughnot 2005, p. 368) But the fifth type of incentive-a guaranteed period of marketed exclusivity for an orphan drug following its regulatory approval-is the most integral to the US orphan drug model. Its duration ranges from a low of five years in Australia to a high of ten years of exclusivity in Japan and European countries, with the US in the middle at seven years. Insofar as orphan drug policies are credited with encouraging new orphan drug production, market exclusivity is widely regarded as the main reason. (Rogoyski 2006) It is therefore important to define market exclusivity relative to other forms of market protection potentially available to orphan therapeutic products. ${ }^{9}$

or not) that targets a life-threatening or serious disease. (Milne and Tait 2009) Indeed, Canada already allows for priority review of applications on this basis. (Lexchin 2012) ${ }^{9}$ The precise details of each form of market protection vary by jurisdiction and are the subject of ongoing dispute. For example, the period of "data exclusivity" afforded to "innovative drugs" under Canada's Food and Drug Regulations (1985) is currently eight years (or 8.5 years for drugs suitable for pediatric populations). In the US, the law was recently amended to provide 12 years of data exclusivity. (FDA 2012) The timeframe in Europe is the same as the US, but the European regulator's decision to create a 
Market exclusivity is, in a broad sense, like any other form of exclusive, marketbased protection available to a drug manufacturer such as a patent right or "data exclusivity" (defined below). In each case, the holder of the patent right or other type of exclusivity has a state-created legal monopoly in respect of a thing, be it information, an invention, or product, that is bounded in time and theoretically enforceable against others.

However, there are differences between these three forms of market protection, in terms of their overall duration, likely point of onset, and effective scope. Whereas patents last for twenty years, market and data exclusivity are typically restricted to a period of twelve years or less. Because patents cannot be granted in respect of publicly disclosed information they must be sought in the early stages of research, often before any clinical trials have begun. Consequently, by the time a drug product receives market approval, the twenty-year patent term may be approaching expiry. ${ }^{10}$ The effective term of a patent averages about 11-12 years. (Rogoyski 2006, p. 8) Having five, seven, or ten years of market exclusivity post approval, eight-twelve years of data exclusivity, or both, is therefore very attractive for manufacturers. In terms of overall scope, data exclusivity is tied to clinical data generated for the purpose of obtaining regulatory approval. It precludes a follow-on competitor from seeking regulatory approval solely on the basis of streamlined pathway for "biosimilars" (also referred to as "follow-on" on "subsequent entry" biologic products) has raised questions about the scope of data exclusivity protection. (Carey 2011) A thorough account of these intricacies is, however, beyond the scope of this paper.

${ }^{10}$ In some jurisdictions, including the US and certain European countries manufacturers can apply for some "patent term restoration" if the regulatory process has been unduly slow. (Drug Price Competition and Patent Term Restoration Act 1984; European Patent Convention 1973) 
establishing the "bioequivalence" of its product to that of a first mover. But it remains open to the follow-on competitor to generate clinical trial data anew and obtain market approval on the basis of that evidence. (Carey 2011) Market exclusivity, on the other hand, means the follow-on competitor cannot, regardless of the source of its clinical trial data, be granted market approval in respect of the same drug—widely construed—for the same indication. (Recall though that same drug can be the subject of multiple different indications). Patent rights are different again. Their precise boundaries can be difficult to discern, in part, because of the inherent challenges in capturing an invention through language, but also, because of patent drafting norms and jurisprudence (e.g. the "doctrine of equivalents") that extend the scope of a patent beyond its literal wording. This level of ambiguity effectively enlarges the patent holder's monopoly unless and until it is successfully tested in court.

There is disagreement as to which of the two forms of exclusivity that come into play outside the regulatory process—-patent rights and market exclusivity under the US Orphan Drug Act-is broader in principle. Peter Arno et al. (1995, p. 235) argue that the market exclusivity confers wider protection against competitors than patents:

The regulations' protection for sponsors of orphan drugs granted exclusivity is, paradoxically, potentially more valuable and generous than a patent owner might receive even through the "doctrine of equivalents" under patent law. Under this doctrine a second drug is the "same," and therefore infringing, only if it is literally either the same as the patent claim or substantially so. Conversely, compounds are different provided that they are not substantially the same (as measured by the precise and express language of the patent claims), although there need not be major differences between the two. The emphasis, therefore, is not on how different they are, but on whether they are literally or substantially alike. In 
contrast, the FDA's regulations require the second drug to manifest "major" differences in order to avoid being the "same" as an existing orphan drug. The regulations, therefore, cast a wider net over what is considered an infringement by one sponsor upon another than does existing patent law. (References omitted)

Robert Rogoyoski (2006, p. 7) claims the opposite:

A patent...is potentially far broader than [Orphan Drug Act] marketing exclusivity, both substantively and temporally. An [Orphan Drug Act] exclusivity grant is roughly equivalent to a method of use patent for a particular substance, plus an injunction. As a stylized example, imagine a novel treatment for neck cancer: Chemical X. Once the first drug company gains orphan drug approval, no other company will also be able to gain FDA approval to market Chemical X to treat neck cancer for seven years. However, [Orphan Drug Act] protection is disorder-specific - another drug developer could get FDA approval to use Chemical X to treat ovarian cancer.

The more fundamental point is that there is nothing preventing a manufacturer from enjoying two, if not all three, of the above forms of market protection, i.e., patent protection, data exclusivity, and market exclusivity. Since 1985 patentability is no bar to orphan drug status and research has shown that most orphan products $(72 \%$ of those approved by the FDA 2001-2003) have patent rights that extend beyond the seven-year period of market exclusivity. (Rogoyoski 2006, p. 11) As well, an increasing percentage of all product approvals, including orphan drugs, are biologics (Coté et al. 2010b) and as a result, under legislation in the US and Europe, enjoy several years of data exclusivity protection. (Biologics Price Competition and Innovation Act 2010; Directive 2004/27/EC of the European Parliament 2004) ${ }^{11}$

${ }^{11}$ In Canada, eight years of data exclusivity is available to "innovative drugs." (Food and Drug Regulations 1985) In the context of trade negotiations with the EU, Canada is currently contemplating further extending the term of data exclusivity. (Beltrame 2012) 
According to one recent analysis, owing to the foregoing incentives, orphan products are becoming more profitable than non-orphan ones notwithstanding the small populations the former supposedly serve. (Meekings et al. 2012) In response, more and more firms are entering into, and allocating resources toward, the orphan disease research space. Economic competitiveness may, as a result, be one factor underlying the Canadian government's recent about face on the need for an orphan drug policy.

\section{c) A Canadian Orphan Drug Framework?}

Canada presently lacks a federal policy focused specifically on orphan drugs but calls for such a policy date back to at least 1992. (Health Canada 1997a) The federal regulator, Health Canada, rejected the call for such a policy in 1997 on several grounds. Health Canada noted that, under existing laws, manufacturers of orphan drugs would likely be eligible for reductions in regulatory fees and 20\% tax credits (Health Canada 1997a, p. 8)—-two incentives typically included in orphan drug laws. Priority reviews are also granted by Health Canada to products targeting life-threatening or seriously debilitating conditions (Health Canada 1997a, p. 11), another incentive described as part and parcel of orphan drug policies. Most importantly, Health Canada found that the vast majority of the 83 drugs then approved as orphan products in the US either received a market authorization from Health Canada $(52)^{12}$ or were made available to patients through a "special access programme" (23). (Health Canada 1997a, p. 16)

\footnotetext{
${ }^{12}$ Note, however, that the report did not assess whether the drugs were approved for the same indication as in the US.
} 
Calls for a federal orphan drug policy have nevertheless continued in Canada, especially in recent years. (Fernandez 2007; Panju and Bell 2010; Gupta 2012) The Canadian Organization for Rare Diseases (CORD) has regularly petitioned the Canadian government for action on the file, holding annual rare disease research day events, and advocating on behalf of patients with rare diseases in various public consultations. (CORD 2013) A private member's bill was also passed in the House of Commons in Canada in 2008, calling for a "national funding approach for drugs for rare diseases." (Canada 2008)

Finally, in October 2012 Canada's Minister of Health announced plans for the development of an "orphan drug framework." (Health Canada 2012a) The government news release relays that a Canadian internet portal to "Orphanet," an international patient registry for rare diseases, will be created in collaboration with the Canadian Institutes for Health Research. (Health Canada 2012b) No other information about the framework has been shared to date but "the proposed framework is in the final design stages and will soon be targeted for public consultation." (Health Canada 2012a)

Notably, two influential bodies—CORD and a Parliamentary Committee-have already articulated, in broad strokes, their own orphan drug policy prescriptions for Canada. Both articulations map onto the US orphan drug model. CORD has, inter alia, called for increased tax credits to make "Canadian-based companies competitive with those in the [US] and other countries, fast-track review of orphan products, and market 
exclusivity "for a specified period of time to facilitate appropriate Return on Investment." (CORD 2005) For its part, on November 1, 2012 the Senate Standing Committee on Social Affairs, Science and Technology published a report entitled Canada's Clinical Trial Infrastructure: A Prescription for Improved Access to Medicines. (Standing Senate Committee on Social Affairs, Science and Technology 2012) With respect to orphan drugs, the Senate Committee recommended:

[T] hat the Minister of Health direct Health Canada to create an Office for Rare Diseases which will be responsible for developing and implementing a comprehensive orphan drug policy in consultation with stakeholders. That policy should include, but should not be limited to:

- granting 'orphan drug status' to drugs in development for specified conditions;

- assisting in the design of clinical trials for investigational orphan drugs;

- eliminating or reducing user fees charged by Health Canada to review drug submissions; and,

- extending market exclusivity for orphan drugs.

CORD and the Senate Committee's recommendations are apt to influence the development of the Canadian orphan drug framework. In Section II of the paper I construct an argument against adopting the US orphan drug model.

\section{Against Adopting the US Orphan Drug Model}

Canada's orphan drug framework should not mirror the US orphan drug model because Canada is in a fundamentally different position today than the US was in 1983 or when other jurisdictions followed suit. Below I present three differences between the past and the present, which, when considered collectively, reveal the (increasing) limitations of the US model's open-ended, market-oriented approach. These differences are: a) the 
proliferation of the orphan drug business model due to increased estimates of profitability, b) the proliferation of newly defined rare diseases due to an abundance of new tools and data from the 'omics sciences, and c) an empirical evidence base concerning the consequences, both intended and unintended, of the US orphan drug model. Together, these differences call into serious question the efficacy of the US orphan drug model.

\section{a) Changed Biopharmaceutical Industries}

Although the incentives included in the US' Orphan Drug Act were significant, at the time the law was passed allocating resources to developing an orphan drug still presented considerable "lost opportunity" costs from an industry perspective. (Spilker 1986, pp. 121-22) Foregoing the development of drugs for larger populations was a powerful disincentive to focusing on orphan drugs.

This forecast appears to have changed in recent years. Today, large, established pharmaceutical companies and emerging biotech firms alike are branding themselves as orphan drug developers. (Frost \& Sullivan 2010) There has been a steady growth in orphan drug markets (increasing by $25.8 \%$ during $2001-2010$ compared to $20.1 \%$ growth for non-orphan drugs), (Meekings et al. 2012) and orphan drug approvals (now constituting roughly a third of all FDA approvals). (Coté et al. 2010b)

There are competing explanations for this shift. One possible explanation is that most of the "low hanging fruit" in drug development have been collected as evidenced by 
reported declines in "new chemical entities" approved by regulators since the mid-1990s. (Light and Lexchin 2012) Another explanation is that firms face increasing competition in therapeutic domains where they have previously achieved "blockbuster" level sales, i.e., sales $>\$ 1$ billion per year. (Light and Lexchin 2012) Acquiring or devoting some inhouse resources toward becoming a so-called "niche buster," that is, manufacturing orphan drugs, is attractive for a number of reasons, first and foremost, the lack of competition from generic drug makers (Seoane-Vacquez et al. 2008) due to the availability of patent rights, data exclusivity, and/or market exclusivity for orphan drugs.

Industry's assessment of the opportunity costs associated with orphan drugs has also changed because 1) clinical trials are likely to be shorter and cheaper due to the smaller patient populations (Wellman-Labadie and Zhou 2010, p. 221); 2) regulators are likely to be more flexible in terms of the safety and efficacy evidence they require for approval (Kesselheim et al. 2011), again, given the nature of the target patient populations; 3) marketing costs are likely to be less, in part, because umbrella rare disease patient organizations can efficiently promote new therapies to specific rare disease communities; 4) there is considerable reputational goodwill to be gained (Wellman-Labadie and Zhou 2010, p. 218); and, 5) manufacturers now appreciate that they can charge premium prices for orphan products because they often address an unmet medical need or life-threatening illness and rare disease organizations will lobby governments for access to orphan drugs despite high prices. (Hemphill 2010) 
Thus, owing to less competition and lower overall costs, orphan drugs are proving exceptionally profitable. Niche busters and blockbusters are not mutually exclusive categories with 43 orphan products achieving such sale levels to date, ${ }^{13}$ and 33 more products reaching global sales in the US \$100-999 million range (Wellman-Labadie and Zhou 2010, pp. 221-222) In fact, a recent analysis suggests that the "revenue generating potential" of orphan products may now exceed that of non-orphan products. (Meekings et al. 2012)

This changed costs equation might motivate a re-assessment of the US orphan drug model's fundamental assumptions; namely, that developing drugs for rare diseases is not a commercially viable proposition. The entry of increasing numbers of biopharmaceutical firms into the orphan disease space can, nonetheless, just as easily be invoked to support the claim that the US model is working-therapies for rare diseases are being prioritized because of the model's incentives. The second and third differences between the past and the present significantly complicate such an inference, however. Consider next the fact that the scope of rare diseases has grown considerably since the advent of the US orphan drug model.

\section{b) Progress Toward "Personalized (Read: Precision) Medicines"}

When the US' Orphan Drug Act was passed by Congress in 1983, sequencing the entire human genome was considered implausible. Today, the Human Genome Project

\footnotetext{
${ }^{13}$ Eighteen (18) of these 43 products were approved solely as orphan products. (Wellman-Labadie and Zhou 2010, p. 221)
} 
has been complete for over a decade, motivating a number of follow-on large-scale 'omics (e.g., genomics, epigenomics, proteomics, metabolomics) projects. The thinking is that this wealth of information will enable the development of "personalized medicines." That is, researchers and companies will use genomic and epigenomic information to stratify individuals with a given disease into discrete sub-populations, which will in turn allow clinicians to make more precise therapeutic decisions. Presently, clinical decisions are largely made without the benefit of such molecular information. As a result, "a substantial proportion of patients are prescribed medications that are, at an individual level, either ineffective or dangerous." (Harper and Topol 2012, p. 1117)

The therapeutic promise of personalized medicine has, with few exceptions, not yet been translated into clinical practice. (Harper and Topol 2012; Tansey et al. 2012) Several factors contribute to the present state of affairs, including strategic behaviour by pharmaceutical companies, limited oversight of genetic testing, lack of reimbursement by healthcare payers, and the complexity of the genomic and epigenomic information itself. (Herder 2013; Herder 2009) Yet, a tipping point may be approaching. Andrew Harper and Eric Topol (2012, p. 1121) argue that "adopting genomically guided clinical trials" could, at once, dramatically reduce the costs of drug development, attrition rates, and unintended harms to patients from prescription medications. While pharmaceutical firms have been slow to embrace this approach, there is evidence that they are incorporating more molecular information into their drug development platforms, if not at the outset, then at least in order to rescue products after a setback when targeting larger, more diverse patient populations. (Carey 2012) 
While improving the chances that a given medicine will work, and do no harm, to patients is a worthwhile objective, the implications of this move toward developing more personalized medicines are more complex for orphan disease policy. In short, new insights from genomics and epigenomics are rendering the boundary between common and rare diseases increasingly mutable, potentially exploding the scope of legislated definitions of orphan disease.

Recent research in the field of breast cancer provides a provocative example. Ten days before plans to develop a Canadian orphan drug framework were announced, a remarkable achievement in the field of breast cancer research was published in the journal Nature. (Network 2012) A network of researchers suggested, after analyzing genetic and epigenetic data from some 800 patients, that all breast cancers could be subdivided into four main types. Presently, breast cancer has an incidence of 96 cases per 100,000 women in Canada, making it the most prevalent form of cancer amongst Canadian women. (Canadian Cancer Society 2012) Imagine that following the Nature study those 96 cases could be divided into four sub-groups of 56 cases per 100,000, 24 case per 100,000, 10 cases per 100,000, and 4 cases per 100,000 people. Further imagine that Canada chooses to adopt Europe's definition of a rare disease, i.e., $\leq 5$ cases per 10,000 members of the population. In that scenario all but the largest sub-group of breast cancers could be classified as rare diseases (with incidence rates of 5.6, 2.4, 1.0, and 0.4 per 10,000 Canadians, respectively). If Canada instead adopted the US' prevalence 
threshold of $\leq 200,000$ people, which equates to roughly 6.5 cases per 10,000 people, (Valverde et al. 2012, p. 2528) all four sub-groups would qualify as orphan diseases.

Commentators have flagged that findings from 'omics fields might transform our understanding and break down accepted classifications of human diseases for some time. (Rai 2001; McCabe et al. 2005; Loughnot 2005; Maher and Haffner 2006) Moreover, orphan diseases have been proliferating in number since the US Orphan Drug Act was passed when roughly 4,000 rare diseases were known; current estimates range from 7,000 to 8,000 rare diseases. (Seoane-Vacquez et al. 2008; Pinxten et al. 2012) Indeed, the pace of rare disease identification is accelerating. According to one source approximately 250 new rare diseases are being identified per year. (Seoane-Vacquez et al. 2008) These gains in knowledge are not unwelcome; on the contrary, they may lead to significant benefits for patients with all manner of diseases. The point, rather, is that the pursuit of personalized medicines significantly complicates the project of prioritizing therapies for rare diseases by bringing into the fold diseases newly describable as orphans because of a greater understanding of the aetiology of a (previously prevalent) disease such as breast cancer.

In the abstract, it is not obvious that orphan disease policy should prioritize diseases that have long been understood as rare over diseases like breast cancer that may soon be sub-divided into multiple rare diseases. Patients with the former may lack any treatment options. But the treatment options for the latter may be of little efficacy and carry significant side effects. Without new and improved treatment options both groups 
of patients can be described as having been "abandoned" or in need of "rescue"- two of the ethical justifications commonly invoked in support of orphan drug policies. (McCabe et al. 2005; Gericke et al. 2005; Gupta 2012; Pinxten et al. 2012)

In reality, each of these groups of patients' claims to scarce resources are empirically comparable. What, for example, is the efficacy of treatments available to individuals afflicted with breast cancer? Rare diseases vary widely in terms of their morbidity and mortality but commonly lack any therapeutic options. As the category opens up to common conditions subdivided into the realm of the rare, this will become less and less the case. The interests of those with rare diseases will, in other words, become increasingly heterogeneous and, assuming finite resources, mechanisms of assessing the potential health impact of pursuing one therapy over another will become increasingly necessary. The fundamental problem with the US orphan drug model in light of developments in the 'omics sciences, then, is that it does not take these empirical complexities into account. $^{14}$

Secondly, assuming it is both necessary and justifiable to privilege some rare diseases over others, there are impediments to doing so in practice. As noted in Section I above, the FDA has tried to curb industry from artificially creating orphan diseases by holding applications for an orphan designation to a "medically plausible" standard.

\footnotetext{
${ }^{14}$ The EU may constitute an exception to this insofar as the targeted disease must be "life-threatening or chronically debilitating" (under the population standard) or "lifethreatening, seriously debilitating or serious and chronic" (under the commercial viability test) to qualify as an orphan drug.
} 
(Maher and Haffner 2006) Such artificial orphan designations are, apparently in the FDA's eyes, contrary to the intent of the Orphan Drug Act and "could divert resources away from research and development of drugs for true orphan diseases and conditions."

(FDA 2011, 64869, italics added) In a set of proposed rules published in the US Federal

Register in 2011, the FDA outlined inappropriate attempts to create such "artificial 'orphan populations:"

For example, some requests for orphan-drug designation have been for a use of a drug in a subset of persons with a particular pathohistologic grade or clinical stage of a specific malignancy, but without a plausible argument why the drug could not be used to safely treat all persons with the malignancy, regardless of disease grade or stage. Another example of misinterpretation of the term "medically plausible" has been its application to a select group of persons with a disease or condition who are eligible to enroll in a clinical trial to support a specific indication for use of a drug when there is no scientific reason to preclude investigational use of the drug in other persons with the disease or condition. Patients who meet inclusion and exclusion criteria for a trial do not automatically qualify as a "medically plausible" subset because it could be medically appropriate to evaluate the same drug for use in the remaining persons with the same disease or condition. Similarly, a [manufacturer's] intention to use or study a drug in a certain limited group of persons with a non-rare disease or condition does not necessarily qualify that group as a "medically plausible" subset. (FDA 2011) (italics added)

Policing the artificial creation of orphan diseases may be difficult given the potential information asymmetries between the FDA and the companies it regulates. Regardless, as implied by the FDA's own statement, subsets of non-rare diseases will not be considered artificial provided that there is a medical or scientific explanation as to why this subset in particular (and not others within the same overarching type of disease) should be targeted for an orphan drug treatment. That is, progress in pharmacogenomics and related fields 
may move artificial sub-divisions into "the arena of scientific fact." (Loughnot 2005, p.

In short, there is increasing noise in the system and the US orphan drug model does not discriminate between diseases provided they meet the statutory threshold of rarity. Progress in the sphere of personalized medicines will leave regulators like the FDA in the unenviable position of distinguishing "true" and transformed orphans ex ante. If past experience is any indication, (Arno et al. 1995; Loughnot 2005) companies are apt to exploit the information asymmetries that will likely exist vis-à-vis regulators in order to maximize their market rewards. ${ }^{15}$ The final subsection details, in empirical terms, the observed effects of those market rewards that comprise the US orphan drug model, which, in tandem with the changes in the biopharmaceutical industries and progress toward personalized medicine, should motivate a new approach to rare diseases in Canada.

\section{c) Impact Unpacked: Production Versus Purpose}

The number of orphan drugs produced before and after the passage of the US Orphan Drug Act is regularly cited as demonstrative of the legislation's positive impact. In the decade prior to its enactment the FDA approved only ten products targeting orphan diseases whereas, in the intervening years, hundreds of orphan products have been

\footnotetext{
${ }^{15}$ For example, the company Amgen sought and received an orphan designation for a drug, epotein alpha (Epogen $®)$, to treat anemia with end-stage renal disease. Following its approval, physicians began prescribing the drug off-label for anemia generally, not just anemia caused by renal failure, and the drug's sales quickly reached blockbuster levels.
} 
licensed. (Haffner 2006) Spikes in orphan drug production in other jurisdictions have been similarly noted. (Pinxten et al. 2012, p. 148) This descriptive evidence only thinly supports the orphan drug legislation's positive influence on orphan drug production. (Kesselheim 2011, p. 466; Seoane-Vacquez et al. 2008) But more rigorous studies, which account for confounding variables, buttress the claim that the US law has motivated an increase—on the order of $69 \%$-in clinical trial research of rare diseases. ${ }^{16}$ (Yin 2008)

This empirical finding begs an important question in light of the growing heterogeneity of rare diseases highlighted above: more trials and drugs for which rare diseases? The available evidence suggests that research and development efforts are skewed in three ways. First, manufacturers tend to focus on diseases that are at the more prevalent end of the spectrum of rare diseases, i.e., diseases affecting 10-50 per 100,000 people as opposed to diseases affecting $0.1-0.9$ per 100,000 people. (Heemstra et al. 2009; Yin 2008) Second, Wesley Yin (2009) found that half of the total response to the Orphan Drug Act was focused on "subdivisions of non-rare diseases" (i.e., diseases reclassified as rare on the basis of molecular information). Third, over time there has been a disproportionate growth in oncology-related orphan drug designations and drug approvals handed out by the FDA as opposed to other therapeutic classes. ${ }^{17}$ (Wellman-Labadie and

\footnotetext{
${ }^{16}$ Interestingly, one study found that there has not been an increase, as measured by publication activity, in rare disease related research more generally. (Heemstra et al. 2009)

${ }^{17}$ Note, it is not possible to say whether there was a disproportionate focus on oncology in terms of the number of orphan drug designations that were sought by manufacturersas opposed to the number granted by the FDA - because those data are not publicly available.
} 
Zhou 2010, pp. 219-221) Olivier Wellman-Labadie and Youwen Zhou (2009, p. 225)

emphasize the significance of this finding:

The vast majority of orphan designations (32\%) were found to relate to cancer. No other therapeutic class was found to account for more than $10 \%$ of orphan designations. In effect, oncology was the only identifiable therapeutic class to demonstrate growth and this growth appears to be the major contributor to the yearly increase in orphan drug designations.

These empirical data points animate three deep concerns with the US orphan drug model. The first is that allowing drugs that target subdivisions of non-rare diseases to qualify as orphan drugs may, in a percentage of cases, be inconsistent with the broadly stated purpose of orphan drug legislation, i.e., to encourage drug development that would not otherwise occur. Using rigorous econometric techniques, Yin (2009, p. 959) estimated that $10 \%$ of clinical trials targeting a subdivision of a non-rare disease would have been undertaken regardless of the incentives offered by the US Orphan Drug Act. This appears to be a modest, even tolerable, inefficiency, but it is important to understand how Yin arrived at this estimate. He compared the number of new clinical trials involving "uncommon non-rare diseases" (i.e., with a prevalence of 200,000 - 500,000) that were subdivided in order to qualify as orphan diseases under the Orphan Drug Act (i.e., with a prevalence of $\leq 200,000$ ) with the number of new clinical trials for uncommon non-rare diseases that were not subdivided over a simultaneous period of time. Whereas the number of new clinical trials targeting subdivided non-rare diseases increased by 185 during the period in question, Yin found that the number of new clinical trials involving non-rare diseases that were not subdivided into orphan diseases decreased by 18 , thus an inefficiency of roughly $10 \%$. Given, however, that most orphan drug designations are 
sought during the final pre-market phase of clinical trials (i.e., phase 3$),{ }^{18}$ (Meekings et

al. 2012, p. 664), Yin's estimate may be conservative. Insofar as Yin's estimate does not

fully account for this tendency to switch streams late in the clinical trials process, in a majority of cases, orphan drugs status appears to serve as an attractive back up pathway to market.

The second concern springs from manufacturers' disproportionate focus on oncology-related rare diseases. Rare diseases afflict similarly small, but diversely disadvantaged, patient populations. Yet, the US orphan drug model's open-ended criteria in no way take this into account. Worse, the model's market incentives, by conditioning in favour of oncology-related products, appear to extend disparities in disadvantage amongst rare disease sufferers. Continuing the quote from above, Wellman-Labadie and Zhou (2010, p. 225) explain:

As stated by Abbey S. Meyers, executive director for the National Organisation of Rare Diseases, "all cancers but four are considered to be rare diseases". Chemotherapy drugs are often effective in several different cancers and off-label use is frequent in the field of oncology. In addition, oncology is among the most lucrative and fastest growing therapeutic classes. Therefore, sponsors appear to concentrate their orphan drug research investments in lucrative fields, such as oncology, to the detriment of other previously unaddressed or under-addressed rare diseases. Such findings question whether so many oncology products should qualify for orphan drug designation and whether so many cancers should be considered as rare diseases. (References omitted) (Italics added)

${ }^{18}$ Note amendments to the Orphan Drug Act in 1988 preclude manufacturers from seeking an orphan designation if they have already applied for market authorization. If, however, they have already received a market authorization for a non-orphan product, they may apply for an orphan designation. (Wellman-Labadie and Zhou 2010, p. 226) 
As illustrated by the breast cancer hypothetical above, even the most common forms of cancer may soon meet the US orphan drug model's population standard owing to progress in molecular biology and 'omics technologies. Cancers are not the public face of rare diseases because they tend to have some treatment options. In fact, the total number of people afflicted by rare diseases (estimated at 350 million worldwide) is often contrasted with the total number of people suffering from cancer and HIV/AIDS (estimated to be less than 350 million) in order to support claims for greater attention to rare diseases. (Global Genes Project 2012) Yet, the US orphan drug model does not discriminate on the basis of relative need or impact. ${ }^{19}$ With most orphan drug therapies clustered around cancers, the level of unmet need across all rare diseases remains at a staggering $\sim 95 \%$. (Coles and Cloyd 2012, p. 195)

This point warrants repetition in light of the first change highlighted in this section of the paper. Despite a marked growth of professed interest in orphan diseases amongst commercial biopharmaceutical entities over the last decade, firms are actually targeting only a narrow breadth of rare diseases.

Therein lies the third and final deep concern with the US orphan drug model. It is possible that Wellman-Labadie and Zhou are mistaken or that the inefficiency identified by Yin represents an acceptable tradeoff, provided that the orphan products that are developed have a greater health impact than rare disease therapies that might otherwise

\footnotetext{
${ }^{19}$ Potentially life-saving or markedly improved products can be granted accelerated regulatory reviews, but these would appear to be likewise available to oncology orphan products.
} 
be developed. In theory, manufacturers' tendency to target more prevalent rare diseases (Heemstra et al. 2009; Yin 2008) might result in greater health impact gains. Fundamentally, though, the issue is that the US orphan drug model does not require manufacturers to postulate a priori whether the health impact of one drug therapy is preferable to others. Relative health impact is, in other words, not amongst the criteria for orphan drug designation. Rather, the manufacturer decides ${ }^{20}$ which amongst the many rare diseases to pursue and there is no obligation for the manufacturer to make its rationale transparent. It is plausible that the manufacturer's decision-making correlates with greater relative health impact although there is currently no empirical evidence to support or refute such a claim. (Kesselheim 2011, p. 469) The manufacturer's decisionmaking must also, by virtue of legal obligations to its shareholders, take profitability into account and the disproportionate focus on oncology orphan products suggests that companies are indeed taking their cues from the financial gains to be had. (WellmanLabadie and Zhou 2010)

Any system will orphan (read: neglect) some diseases compared to others absent unlimited resources, capacity, and time. The salient questions should be why and how should some diseases be neglected or, conversely, prioritized relative to others. Under the US orphan drug model, market forces dictate priorities and no attempt is made to discern at the outse $\mathrm{t}^{21}$ whether such priorities correlate with health impact gains for persons with

\footnotetext{
${ }^{20}$ Putting aside the influence of the FDA's orphan drug grant program and other research funding available to researchers and manufacturers engaged in the orphan disease space.

${ }^{21}$ Arguably, this screening occurs at the reimbursement stage and companies are aware of which products are more or less likely to be attractive to payers and make upstream
} 
rare diseases. The expanded commercial interest in orphan disease and potential explosion of rare diseases owing to advances in 'omics fields of science promise to intensify this problem. A different model to encourage therapies for rare diseases is therefore needed. In Section III of the paper I examine several options.

\section{Departing From Business As Usual}

As signaled in the introduction, there remains room to debate whether rare diseases should be prioritized at all (McCabe et al. 2005) or relative to neglected diseases that afflict swaths of the world's poor. But if the policy question in Canada is shifting from whether to how to generate treatment options for those who suffer from rare diseases, then two broad options, encompassing four discrete policy models, merit consideration. In this penultimate section of the paper I contrast the two broad policy options as a) adopting the US orphan drug model plus a series of contingency measures, i.e., passing an Orphan Drug Act 2.0, versus b) instituting one or more of three hybrid public-private incentive models. I argue in subsection c) generally in favour of the latter set of options in light of the limitations of the US orphan drug model presented above.

\section{a) An Orphan Drug Act 2.0}

resource allocation decisions accordingly. However, a great deal of evidence suggests that manufacturers, in response to market incentives, expend the majority of their resources developing and marketing "me too" products and, despite the absence of significant therapeutic gains, payers in Canada and elsewhere often elect to reimburse these products. (Grootendorst et al. 2011; Light and Lexchin 2012) There is thus a need to incorporate stronger assessments of value and impact as part of upfront innovation design. (Lehoux et al. 2008) 
Blockbuster sales and gaming of the orphan drug designation process have motivated several proposals for reform of the US Orphan Drug Act. All of these proposals involve building contingency measures into a kind of Orphan Drug Act 2.0. Such measures include the legal authority to terminate market exclusivity; recouping a small percentage of profits if sales achieve a particular level; stronger pricing controls if and when an orphan product achieves excessive sales; using a sliding scale of incentives such that the incentives (e.g., duration of market exclusivity) adjust as a function of the rarity of the disease; and/or lowering the prevalence- or incidence-based threshold of rare disease. (Loughnot 2005; Wellman-Labadie and Zhou 2010; Hollis 2005)

Several of these contingency measures are already in place in jurisdictions with orphan drug laws. Japan, for instance, has a $1 \%$ claw back clause for orphan products that exceed 100 million yen (approx. \$US 1.1 million) in annual sales. (Thamer et al. 1998) The EU has the authority to take away market exclusivity after it has been granted if the drug in question is used for non-orphan treatment purposes although this measure has never been invoked. (Wellman-Labadie and Zhou 2010)

\section{b) Three Hybrid Public-Private Incentive Models}

A more meaningful expression of commitment to aiding those who suffer from rare diseases that are neglected by market imperatives would be to move away from the US orphan drug model's near-complete deference to market-driven decision-making. There are three models that fit in this category, all of which combine, to varying degrees, existing private firm resources with public sector incentive and decision-making 
mechanisms. In theory, the US orphan drug model might be similarly described: market exclusivity is, for example, an incentive provided by the state. The difference is, in each of the three models presented below, the public sector has, relative to the US orphan drug model, a stronger, more discriminating role in determining for whom and for what purposes the incentives will be made available.

\section{i. $\quad$ Modified-Health Impact Fund}

A first hybrid-type proposal is to borrow from the Health Impact Fund (HIF) model currently proposed to facilitate access to "essential medicines" that are currently unaffordable to poorer peoples of the world. (Banerjee et al. 2010; Pogge 2005; Grootendorst et al. 2011) The HIF is premised on the idea of "paying for performance," that is, decoupling the price of essential medicines from the financial rewards to be gained. At present, manufacturers set price points for medicines in order to maximize financial rewards; they often bear little relationship to the actual costs of drug production. Yet, price points are seldom high enough in low and middle-income countries to make drug production for those markets worthwhile to large pharmaceutical manufacturers. Under the HIF proposal, in exchange for making a medicine available almost at cost, and thus affordable in low and middle-income countries, manufacturers are to be rewarded by way of annual payments from pooled governmental funds based on the measured health impact of that medicine. Politically, the key advantage of the HIF proposal is that it is a supplement-not a substitute-to existing incentives such as the patent system. It is an opt-in system. The key challenge is to make it worthwhile, financially, for companies to allocate their resources towards essential medicines for the poor. 
The HIF was not put forth to address rare diseases although they were invoked as another example of the bias that market-based rewards carry. (Peterson et al. 2010; Pogge 2005) The HIF, rather, aims to reward companies in terms of health impact, measured by reductions in the global burden of disease through making essential medicines available at cost to large numbers of poor people. To adapt the HIF to the context of rare diseases would require weighting (e.g., to the power of 1.5) the measurement of health impact in favour of medicines that have a significant impact in each patient who suffers from a rare disease (as opposed to the global burden of disease).

\section{ii. Grant-and-Access Pathway}

To encourage new therapies for a wider spectrum of rare diseases, Ana Valverde, Shelby Reed and Kevin Schulman (2012) have proposed a government sponsored "grantand-access" funding pathway (with pricing controls). The central premise of their proposal is that, under the current US Orphan Drug Act, several would-be contributors (i.e., universities, start-up companies, and smaller biotech firms) to orphan drug development cannot take advantage of the law's generous 50\% tax because they often lack a "revenue stream from existing products." Consequently, the primary upfront benefit of the legislation is only available to more established players, so multinational pharmaceutical firms and larger biotechs dominate orphan drug designations and approvals. (Wellman-Labadie and Zhou 2010) Valverde et al. (2012, p. 2530) propose replacing tax credits with a substantially more robust grant program, the recipients of which would be required to adhere to "pricing caps for [any resulting] orphan drugs based 
on how long drug development took and how much it cost, expected market size, and the target internal rate of return." In theory, this "grant-and-access pathway, in which access refers to patients' access to affordable drugs" (Valverde et al. 2012, p. 2530) would open up orphan drug development to a range of new actors, which would, in turn, contribute to a wider range of rare diseases-particularly the rarest of rare diseases—-than larger firms have thus far been inclined to focus upon.

\section{iii. Publicly Funded Trials}

A third hybrid model is for the government to directly fund clinical trials of orphan drugs for rare diseases rather than funding academic researchers in the hopes that they will partner with industry, which will, in turn, sponsor a drug through clinical trials all the way to regulatory approval. While the idea of publicly funding later phases of research, inclusive of phase 3 clinical trials, has been regularly raised in response to pharmaceutical market failures, there are competing versions of how it would work. One version put forward by Dean Baker (2008, p. 734) for the US context requires the creation of a "network of independent companies, operating on long-term federal contracts (8 to 12 years)" administered by the FDA, the National Institutes of Health, or some other specially created government agency. Other versions of publicly funded clinical trials envision the research being undertaken by the government in-house (Jayadev and Stiglitz 2008, p. 167) or by non-profit consortia comprised of existing members of industry, nonprofit research, and government researchers. (Grootendorst et al. 2011, p. 683) Integral to all of these versions is a greater degree of openness with clinical trial findings than the status quo. Specifically, Baker (2008, p. 735) and others 
(Grootendorst et al. 2011, p. 683) would require that clinical trial data and findings be placed in the public domain. This dissemination requirement appears to distinguish this model from the grant-and-access pathway proposed by Valverde et al. (2012), which only requires grant recipients to adhere to pricing caps. ${ }^{22}$ Otherwise, the two models appear very similar in principle.

\section{c) Comparing the Four Policy Models}

There are a variety of potential advantages and disadvantages associated with the four policy models. (See Table 2 below, integrating some of the features described above) Here, I group these advantages and disadvantages under the headings of i) pragmatic and ethical considerations, and ii) fiscal and political considerations. While I argue that creating an Orphan Drug Act 2.0 in Canada would be a policy mistake, I do not take a strong position on which of the other three models is preferable. Instead, which, or what combination of, these three models should be instituted must depend on future public consultations.

\section{i. Pragmatic and Ethical Considerations}

Creating an Orphan Drug Act 2.0 carries significant pragmatic and ethical disadvantages in my view. Contingency measures such as a claw back clause may mitigate specific instances of abuse such as an extraordinarily high priced orphan drug.

${ }^{22}$ It should be noted, though, that manufacturers are subject to increasing legal requirements to register and share their clinical trial findings. These requirements are far from perfect, (Vera-Badillo et al. 2013; Viergever and Ghersi 2011; Law et al. 2011; Sekeres et al. 2008) but would presumably apply to firms participating in Valverde et al.'s grant-and-access pathway. 
However, none alters the open-ended nature of orphan disease criteria, and none changes the market-based mechanism of encouragement. Lowering the applicable threshold of orphan disease or offering more or less incentives on the basis of rarity remain prone to gaming by industry, perhaps increasingly so, with continued progress in the 'omics sciences. Policing the boundaries of "rare disease" and "same drug" will also likely place an increasing burden upon regulators. Fundamentally, creating an Orphan Drug Act 2.0 reduces to tinkering with the status quo and there is no evidence to suggest that such a course of action will result in therapies for a broader range of rare diseases than witnessed to date.

While preferable to an Orphan Drug Act 2.0 insofar as they should allow for priorities other than profit to guide decision-making, the three hybrid policy models also carry pragmatic and ethical challenges. For example, the modified-HIF's weighted measurement of health impact may be difficult to decide upon. While at times contentious, measuring the global burden of disease (as proposed by the HIF for neglected diseases) can at least avail of standardized techniques (e.g., quality of adjusted life years, or "QALYs"). There is, in contrast, no standardized approach to measuring the health impact of rare disease interventions in development, ex ante, just as there is uncertainty, ex post, as to what evidentiary criteria, values, and deliberative processes healthcare payers should employ in deciding which interventions, once made, to reimburse. (Drummond et al. 2009; Hollis 2006) 
The grant-and-access pathway and publicly funded clinical trials proposals both seem to lean heavily on peer review systems to identify worthwhile projects. Concerns about the direction, values, and integrity of Canadian research funding bodies and, by extension, their peer review processes, have, however, been mounting for some time. (Baylis 2012; Silversides 2010; Tyers et al. 2005) If the purpose of the Canadian orphan drug framework is to stimulate research into rare diseases for ethical or value-based reasons (e.g., equity), then it would behoove policy-makers to somehow integrate such considerations into the decision-making process. This could, in part, be achieved by involving members of diverse publics, perhaps including individuals with rare diseases, in the deliberations of either kind of funding program. Promoting public participation and designing deliberative processes is complex but precedents do exist to draw from. (Avard et al. 2009) Such deliberative processes could also help construct ways of measuring health impact in a modified-HIF. At the same time, rare disease patients' direct stake in the research complicates any role they might have in deciding which trials to fund or reward through a modified-HIF mechanism. The degree to which individuals with rare diseases and/or rare disease patient organizations - which already maintain close relationships with regulators, research funding entities, and biopharmaceutical companies (Dunkle et al. 2010) — should participate in orphan disease policy models therefore requires careful delineation. Creating a space for members of different patient populations, rare or common, as well as other Canadian publics to be involved in the decision-making can also serve an important democratic purpose, legitimizing difficult choices in respect of finite healthcare resources. (Daniels 2000; Daniels and Sabin 1997) 
An enhanced level of public input is the central ethical advantage and pragmatic challenge of all three hybrid policy models. Relative to the US orphan drug model's deference to decision-making in the marketplace, building a public square into upstream allocations of resources and/or introducing more ethical, value-based criteria into the process is simply a more just way of making inevitably hard choices. To integrate modes of public participation and/or criteria that speak to the relative health impact of one orphan drug compared to others into a modified-HIF, grant-and-access pathway, or system of publicly funded trials, is to take more seriously the growing number of and, heterogeneity of interests involved in, rare diseases.

\section{ii. $\quad$ Fiscal and Political Considerations}

The remaining reasons not to pursue one or more of the three hybrid policy models are fiscal or political in nature. The upfront costs of the modified-HIF, grant-andaccess pathway, and publicly funded clinical trials may be seen as considerable. I have two responses to such a concern.

First, in anticipating the upfront costs of running one or more of these programs, particularly the grant-and-access pathway and publicly funded clinical trials, it is important to factor in the fact that the Canadian government already heavily subsidizes $(\sim 50 \%)$ the costs of clinical trials through tax credits. (Grootendorst et al. 2011, p. 683) The costs of paying for a grant-and-access pathway or publicly funding clinical trials would not surpass the value of such tax credits. On the contrary, as Valverde et al. (2012, p. 2533) point out, the "tax credits [provided under the US Orphan Drug Act] are valued 
at $\$ 400$ million per year, an amount that could provide approximately $\$ 4.5$ million in funding...for almost ninety new drug development programs per year." The value of tax credits in Canada would be considerably less but sufficient to fund several multi-million dollar research projects. These may seem like meager sums in view of the (inflated) $>\$ 1$ billion estimated costs of drug development. (Light and Lexchin 2012) Keep in mind, though, if the target patient population is small from the outset, then clinical trial costs can diminish from the hundreds to tens of millions of dollars (or less). Of course, the money for a government-funded grant-and-access pathway or clinical trials will have to come from government sources. It is nevertheless important to be clear about the opportunity costs of buying into the US orphan drug model with tax credits on par with the US legislation. Instead of funding a suite of research projects carried out by new actors, ideally selected with the benefit of public input, Canada would be choosing to give tax credits to established manufacturers with known tendencies to address only a limited, lucrative subset of rare diseases.

Second, estimates of the upfront costs associated with implementing one of the three hybrid policy models should not discount the downstream costs associated with the adoption of an Orphan Drug Act 2.0. Such downstream costs come in two kinds; namely, the public health costs that can flow approving orphan drugs of questionable safety and efficacy; and, rising costs to provincial healthcare budgets.

Two recent studies suggest the evidence behind approved orphan medicines for cancers (Kesselheim et al. 2011) and neurological conditions (Mitsumoto et al. 2009) 
depart from important experimental standards. Specifically, orphan drug trials are less likely to be blinded and randomized than non-orphan drug trials. While these departures may stem from the practical difficulties of conducting large clinical trials with small subpopulations or individuals afflicted with rare diseases, the absence of randomization and blinding in orphan drug trials "can lead to identifying benefits that are not real or missing risks that are." (Kesselheim et al. 2011) This raises doubts about the safety and efficacy of orphan drugs, not only for those with rare diseases, but others as well, as orphan drugs, particularly in oncology, are known to be prescribed off label to larger populations. ${ }^{23}$ (Kesselheim 2011, p. 468) Yin (2009, p. 958) found this to be especially the case for orphan drugs targeting subdivisions of non-rare diseases, implying that such drugs are developed strategically to take advantage of physicians' ability to prescribe off-label.

There is no guarantee that safety and efficacy would not attend orphan products resulting from publicly funded research or in response to the modified-HIF's incentives. ${ }^{24}$ The difference is that the evidence base behind approved, publicly funded orphan products would be open to independent interrogation. As noted above, this is the feature of publicly funded trials that sets it apart from the other two hybrid models. (See Table 2)

\footnotetext{
${ }^{23}$ Another study found that orphan drugs were less likely to be associated with a postmarket safety concern. However, orphan drugs approved on an expedited timeframe were found to have a higher incidence of safety issues identified by a regulator. (Heemstra et al. 2010) Although not specific to orphan drugs, a recent study of approved products by Health Canada over a fifteen-year period, found a marked increased in safety warnings for fast-tracked drugs. (Lexchin 2012)

${ }^{24}$ Currently, Health Canada has limited powers to require and carry out post-market surveillance of prescription pharmaceuticals. Efforts to remedy this have been proposed for some time but little has changed in terms of post-market surveillance since a bill to amend Canada's Food and Drug Act died on the order paper in 2008.
} 
An Orphan Drug Act 2.0 would not alter the level of secrecy and poor reporting that presently surrounds clinical trials despite registration requirements, (Vera-Badillo et al. 2013; Law et al. 2011; Viergever and Ghersi 2011; Sekeres et al. 2008) creating enormous amounts of wasted research and, in some cases, avoidable harm to patients. (Herder 2012) The costs of dealing with adverse events associated with prescription medications are substantial. (Hohl et al. 2011)

The second downstream cost that should be part of the calculus stems from the prices that orphan drugs tend to command. Due to the various market protections they enjoy under the US orphan drug model and the ostensibly small populations they are intended for, orphan drugs are subject to less competition from generic drug manufacturers. (Seoane-Vazquez et al. 2008) As a result, they tend to carry an exceptionally high price tag, in turn, raising questions of sustainability for healthcare payers and access to medicines for rare disease patients in the US and Europe. (Valverde et al. 2012, p. 2530; Kesselheim and Solomon 2010, p. 2046; Simoens 2011) If Canada's orphan drug framework were to copy the US orphan drug model, following CORD and the Canadian Senate Committee's recommendation to create market exclusivity for orphan drugs, it is likely that the same questions of sustainability and access would arise. ${ }^{25} \mathrm{~A}$ growing proportion of provincial healthcare budgets in Canada are already

${ }^{25}$ There is debate about whether more personalized medicines more generally will increase health care costs. Tailored treatments already on the market such as trastuzumab (Herceptin ${ }^{\circledR}$ ) tend to command exceptionally high prices. But the ability to discriminate responders and non-responders to a therapy potentially offers significant cost-savings, assuming the clinical validity of the discriminating test. (Deverka et al. 2010; Davis et al. 2009; Stallings et al. 2006) Based on the data that currently exists it is not possible to say that orphan drugs are cost-effective, however. (Kesselheim 2011, p. 469) 
allocated to pharmaceuticals. (Morgan et al. 2005) Orphan drugs will either exacerbate this spending problem or lead to an increasing number of drugs that are clinically required, but excluded from provincial drug formularies, in turn, placing the burden of drug costs upon those with rare diseases. The risk of either eventuality supports the move to fold other criteria and perspectives into the drug development process instead of waiting until reimbursement decisions are made.

Not doing so highlights the first of several political risks associated with endorsing (or not) the US orphan drug model: harm to federal-territorial-provincial relations. In Canada, both levels of government make policy relevant to drug therapies. Whereas the federal government has through its criminal law power jurisdiction to regulate controlled substances such as pharmaceuticals, the provision of healthcare services, including drug therapies, is a matter of provincial or territorial jurisdiction. If the Canadian federal government were to pass an Orphan Drug Act 2.0, precipitating, in time, further increases in healthcare service expenditures, there is a risk that the federalterritorial-provincial relations regarding healthcare would be further aggravated. Provincial and territorial governments can, of course, choose not to publicly fund orphan drugs. However, patient organizations like CORD can put significant pressure on payers to reimburse orphan disease treatments, especially those perceived as life-saving drugs. (Carpenter and Fendrick 2004) If, instead, the federal government created a modifiedHIF (requiring manufacturers to make medicines available virtually at cost), grant-access pathway (requiring grant recipients to agree to pricing caps), or publicly funded clinical 
trials, there is a better chance that the federal government's orphan drug framework will not erode provincial and territorial healthcare budgets.

Implementing a modified-HIF, grant-and-access pathway, or publicly funding orphan drug trials carries its own political risks. Each is out of step with the US orphan drug model, therefore, implementing any one of these policy proposals may be perceived as inconsistent with broader efforts to "harmonize" national drug regulation systems and intellectual property standards. (ICH 1996; Health Canada 1997b; TRIPS 1994) Regulators in jurisdictions with orphan drug laws in place have created "common" application forms for orphan drug designation. (FDA 2013) Industry may thus complain if Canada's orphan drug framework substantially departs from existing regulatory regimes.

Harmonization is not, however, a value in and of itself. (Lexchin 2011) And the shortcomings of the US orphan drug model caution against harmonization if the objective is to address and provide affordable therapies for a wider range of rare diseases. Moreover, two of the three hybrid policy models (with the modified-HIF as the exception) are predicated on supporting new researchers and research entities all the way through the later phases of orphan drug development, on the assumption that they would, on balance, diversify the clinical trial landscape of rare disease research. Such researchers and entities are not practiced in the procedures of existing orphan drug laws. Therefore the absence of harmonization with other jurisdictions should, in principle, be of little concern to these actors. 
Finally, by virtue of funding the later phases of drug development, which carry high rates of attrition $(\sim 15 \%$ of drugs submitted to regulators are approved for sale (Valverde et al. 2012)), there is a risk that clinical trial research will become increasingly politicized. The best response to this risk is, however, to ensure that the issues of research integrity and conflict-of-interest that currently plague the pharmaceutical industry do not colour funding decisions under whichever hybrid policy model is implemented.

In the end, the foregoing pragmatic, ethical, fiscal, and political considerations (summarized as stylized advantages and disadvantages in Table 2 below) militate against adopting the US orphan drug model, whether updated to a version 2.0 or not. Health Canada has stated that Canada's orphan drug framework will be developed through a public consultation process. In my view, this process should carefully consider the advantages of each of the three hybrid policy models and embrace the challenge of building deliberative elements with input from diverse, interested publics, guided by ethical, value-based criteria, into one, or some combination, of these three policy models.

Table 2. Stylized Advantages and Disadvantages of Four Policy Models.

\begin{tabular}{l|ll}
\hline Model & Advantages & Disadvantages \\
\hline Orphan Drug Act 2.0 & Political Feasibility & $\begin{array}{l}\text { Expanding Scope } \\
\text { Market-Driven Priorities } \\
\end{array}$ \\
& & Safety and Efficacy Issues \\
& & Healthcare System Costs \\
& & \\
& Pricing Control & Political Will \\
& Greater Public Input & Upfront Costs \\
& More Equitable Distribution & Measurement Challenges \\
\hline
\end{tabular}




\begin{tabular}{|c|c|c|}
\hline Model & Advantages & Disadvantages \\
\hline & \multicolumn{2}{|l|}{ of Health Benefits } \\
\hline Grant-and-Access Pathway & $\begin{array}{l}\text { New Players } \\
\text { Pricing Control } \\
\text { Greater Public Input } \\
\text { More Equitable Distribution } \\
\quad \text { of Health Benefits }\end{array}$ & $\begin{array}{l}\text { Political Will } \\
\text { Upfront Costs } \\
\text { Peer Review Challenges }\end{array}$ \\
\hline $\begin{array}{l}\text { Publicly Funded Clinical } \\
\text { Trials }\end{array}$ & $\begin{array}{l}\text { New Players } \\
\text { Pricing Control } \\
\text { Greater Public Input } \\
\text { More Equitable Distribution } \\
\text { of Health Benefits } \\
\text { Open Scientific Data }\end{array}$ & $\begin{array}{l}\text { Political Will } \\
\text { Upfront Costs } \\
\text { Peer Review Challenges }\end{array}$ \\
\hline
\end{tabular}

\section{Conclusion}

The argument advanced in this paper was as follows. I began by showing that the US orphan drug model does not, on its face, discriminate amongst rare diseases, apart from set prevalence- or incidence-based thresholds of rarity. Yet, in practice the US orphan drug model is highly discriminating. Specifically, diseases that can, through 'omics data and technologies, be recast as rare, or belong to the larger, more lucrative therapeutic class of oncology products, find favour within the US orphan drug model. Therefore, if the purpose of an orphan drug policy is to reallocate resources on the basis of criteria beyond commercial viability and profitability—but instead commitments to values such as equity-, then a different approach to rare, orphan diseases is needed. This need is, moreover, pressing given increasing interest amongst biopharmaceutical 
companies in the orphan disease space as well as advances toward more personalized medicines promising to increase the number and heterogeneity of rare diseases.

Unlike many current rare diseases, which, by definition, lack therapeutic options, in the future, patients with newly characterized rare diseases may, as members of an overarching, more prevalent form of disease, have some therapeutic options. Comparing such competing claims to researchers and research institutions' limited resources should happen upfront otherwise the narrow focus on only certain rare diseases is likely to remain. The US orphan drug model's open-ended, market-oriented criteria will not do this work. A modified-HIF, which aims to reward manufacturers based on performance rather than market logic, a grant-and-access pathway, which aims to open up orphan drug development to new researchers and entities, or a system of publicly funding clinical trials of rare disease therapies, which aims to avoid the practices of industry drug developers, all, in principle, offer greater opportunities for public deliberation and ethical evaluation. Defining with greater precision how one, or some combination, of these three policy models should operate in the service of rare diseases is a matter for future analysis and public consultation.

The call made here to integrate deliberative processes and ethical, value-based criteria into orphan drug policy mechanism(s) in order to more selectively support the upstream phases of therapeutic development warrants emphasis. This call contrasts with the literature to date, which, to the extent that it recognizes a disconnect between the criteria employed for orphan drug designation (at the regulatory stage) and the criteria 
used by healthcare payers (at the reimbursement stage), focuses almost exclusively on public deliberation and ethical criteria as tools to better inform reimbursement decisions by payers. (Menon and Stafinski 2008; Menon and Stafinski 2011; Menon et al. 2011; Drummond et al. 2007; Drummond et al. 2009; Winquist et al. 2012; Hollis 2006; Rai 2001) I assumed based on the work of others, at the outset of the paper, that more reflective screening early on carried positive outcomes; namely, legitimizing choices that will advantage some rare diseases relative to others, (Daniels 2000; Daniels and Sabin 1997) and, over time, precipitating more valuable healthcare innovations. (Lehoux et al. 2008) But I have also argued throughout—in the negative—that Canadian endorsement of the US orphan drug model portends adverse consequences. In particular, adopting the US orphan drug model may exacerbate already escalating levels of provincial healthcare expenditures on biopharmaceuticals or else further privatize the high costs of orphan drugs. Secondly, the US orphan drug model may add to increasing safety and efficacy related concerns in drug regulation. (Kesselheim et al. 2011) Fast-tracked drug approvals, which many orphan drugs would qualify for, already account for a disproportionate number of post-marketing safety concerns in Canada. (Lexchin 2012) Given the challenges inherent in conducting clinical trials with small populations, having robust post-marketing oversight in place is of paramount importance. Yet, Canada's postmarketing oversight systems are demonstrably poor. (Flood and Dyke 2012; Senate Standing Committee on Social Affairs, Science and Technology 2013) The US orphan drug model does nothing to improve the transparency and quality of the evidence base upon which the safety and efficacy of medicines are judged and continuously monitored. 
Despite industry's recent strategic orientation toward orphan diseases and future progress in the 'omics sciences, not everyone will have some form of orphan (read: rare) disease. But putting into place a system like the US orphan drug model that is apt to generate less than affordable drug therapies, the safety and efficacy of which we will know less about, risks orphaning (read: neglecting) many more. In anticipation of these growing sources of neglect, Canadian policy-makers should take up the challenge of designing an alternative orphan drug policy mechanism. Although seldom acknowledged, there is already convincing evidence that interest groups and other factors influence therapeutic development and regulation. (Abraham and Sheppard 1999; Trotta et al. 2011) The challenge is to design a system that is actually accountable to the commitments motivating a public policy for rare diseases in the first place; and this is not US orphan drug model. 


\section{References}

Abraham, John, and Julie Sheppard. "Complacent and Conflicting Scientific Expertise in British and American Drug Regulation: Clinical Risk Assessment of Triazolam.” Social Studies of Science 29, no. 6 (December 1, 1999): 803-843.

Anon. (2012). “Tories Chose Patent Protection over Children's Lives in Defeating Drug Bill: Stephen Lewis.” The Globe and Mail. Accessed December 8, 2012.

http://www.theglobeandmail.com/news/politics/tories-chose-patent-protection-overchildrens-lives-in-defeating-drug-bill-stephen-lewis/article5827019/.

Arno, Peter S., Karen Bonuck, and Michael Davis. "Rare Diseases, Drug Development, and AIDS: The Impact of the Orphan Drug Act." The Milbank Quarterly 73, no. 2 (January 1, 1995): 231-252. doi:10.2307/3350258.

Avard, Denise, Lucie Bucci, Michael Burgess, Jane Kaye, Catherine Heeney, Yanick Farmer, and Anne Cambon-Thomsen. "Public Health Genomics (PHG) and Public Participation: Points to Consider.” Journal of Public Deliberation 5, no. 1 (May 15, 2009). http://www.publicdeliberation.net/jpd/vol5/iss1/art7.

Baker, Dean. "The Benefits and Savings from Publicly Funded Clinical Trials of Prescription Drugs." International Journal of Health Services: Planning, Administration, Evaluation 38, no. 4 (2008): 731-750. 
Banerjee, Amitava, Aidan Hollis, and Thomas Pogge. "The Health Impact Fund: Incentives for Improving Access to Medicines.” The Lancet 375, no. 9709 (January 2010): 166-169. doi:10.1016/S0140-6736(09)61296-4.

Baylis, Francoise. "Knowledge: The Best Return on Investment | The Mark News." Accessed January 19, 2013. http://www.themarknews.com/articles/8299-knowledge-thebest-return-on-investment/\#.UPsL2OjNCt4.

Beltrame, Julian. "Will Canada-EU Trade Deal Keep Generic Drugs Off Shelves?" The Huffington Post. Accessed January 19, 2013.

http://www.huffingtonpost.ca/2012/09/16/canada-eu-trade-drug-patents_n_1888492.html.

Biologics Price Competition and Innovation Act. (2010). Pub. L. No. 111-148, § 7001, 124 Stat. 804, codified at 42 U.S.C. $\$ 262(\mathrm{k})(7)(\mathrm{A})$.

Bohrer, Robert A., and John T. Prince. "A Tale of Two Proteins: The FDA's Uncertain Interpretation of the Orphan Drug Act." Harvard Journal of Law \& Technology 12 (Winter 1999): 365-417.

Canada. (2008). House of Commons. Debates 142, no. 078, 2d Session, $39^{\text {th }}$ Parliament. 2008 April 14, p. 4847-4849. 
Canadian Cancer Society. (2012). Breast cancer statistics at a glance.

http://www.cancer.ca/canada-

wide $/$ about $\% 20$ cancer/cancer $\% 20$ statistics $/$ stats $\% 20$ at $\% 20 \mathrm{a} \% 20$ glance $/$ breast $\% 20$ cancer. $\operatorname{aspx}$

Canadian Organization for Rare Disorders. (CORD). (2013). News and Events. $\mathrm{http}: / /$ raredisorders.ca/newsEvents.html.

Canadian Organization for Rare Disorders. (CORD). (2005). Position Paper on Canada's Orphan Drug Policy. http://raredisorders.ca/currentIssues.html.

Carey, Karen. “Avastin Loses Breast Cancer Indication.” Nat Biotech 30, no. 1 (January 2012): 6. doi:10.1038/nbt0112-6a.

Carey, Karen. "Biosimilars Encircle Rituxan, US Debates Innovator Exclusivity." Nat Biotech 29, no. 3 (March 2011): 177-178. doi:10.1038/nbt0311-177.

Carpenter, Daniel, and Mark Fendrick. “'Accelerating Approval Times for New Drugs in the U.S'." The Regulatory Affairs Journal - Pharma 15, no. 6 (2004): 411-417.

Cheung, Richard Y, Jillian C Cohen, and Patricia Illingworth. “Orphan Drug Policies: Implications for the United States, Canada, and Developing Countries." Health Law Journal 12 (2004): 183-200. 
Coles, L. D., and J. C. Cloyd. "The Role of Academic Institutions in the Development of Drugs for Rare and Neglected Diseases." Clinical Pharmacology \& Therapeutics 92, no. 2 (2012): 193-202. doi:10.1038/clpt.2012.83.

Coté, Timothy R, Kui Xu, and Anne R Pariser. “Accelerating Orphan Drug Development." Nature Reviews. Drug Discovery 9, no. 12 (December 2010): 901-902. doi:10.1038/nrd3340. (Coté et al. 2010a)

Coté, Timothy, Aditya Kelkar, Kui Xu, M. Miles Braun, and M. Ian Phillips. “Orphan Products: An Emerging Trend in Drug Approvals." Nature Reviews Drug Discovery 9, no. 1 (January 1, 2010): 84-84. doi:10.1038/nrd2546-c1. (Coté et al. 2010b)

Daniels, N. “Accountability for Reasonableness.” BMJ 321, no. 7272 (November 25, 2000): 1300-1301. doi:10.1136/bmj.321.7272.1300.

Daniels, Norman, and James Sabin. "Limits to Health Care: Fair Procedures, Democratic Deliberation, and the Legitimacy Problem for Insurers." Philosophy \& Public Affairs 26, no. 4 (1997): 303-350.

Davis, Jerel C., Laura Furstenthal, Amar A. Desai, Troy Norris, Saumya Sutaria, Edd Fleming, and Philip Ma. “The Microeconomics of Personalized Medicine: Today’s 
Challenge and Tomorrow's Promise." Nature Reviews Drug Discovery 8, no. 4 (April 1, 2009): 279-286. doi:10.1038/nrd2825.

Deverka, Patricia A., John Vernon, and Howard L. McLeod. “Economic Opportunities and Challenges for Pharmacogenomics." Annual Review of Pharmacology and Toxicology 50, no. 1 (February 2010): 423-437.

doi:10.1146/annurev.pharmtox.010909.105805.

Directive 2004/27/EC of the European Parliament and the Council of 31 March 2004 amending Directive 2001/83/EC on the Community Code relating to medicinal products for human use, Office Journal of the European Union L136, 30/4/2004, P.0034-0057.

Drug Price Competition and Patent Term Restoration Act. (United States). (1984). 98th Congress, P.L. 98-417, 98 Stat. 1585.

Drummond, Michael, Bill Evans, Jacques LeLorier, Pierre Karakiewicz, Douglas Martin, Peter Tugwell, and Stuart MacLeod. "Evidence and Values: Requirements for Public Reimbursement of Drugs for Rare Diseases--a Case Study in Oncology." The Canadian Journal of Clinical Pharmacology = Journal Canadien De Pharmacologie Clinique 16, no. 2 (2009): e273-281; discussion e282-284.

Drummond, Michael F, David A Wilson, Panos Kanavos, Peter Ubel, and Joan Rovira. "Assessing the Economic Challenges Posed by Orphan Drugs." International Journal of 
Technology Assessment in Health Care 23, no. 1 (2007): 36-42.

doi:10.1017/S0266462307051550.

Dunkle, Mary, Wayne Pines, and Peter L Saltonstall. "Advocacy Groups and Their Role in Rare Diseases Research." Advances in Experimental Medicine and Biology 686 (2010): 515-525. doi:10.1007/978-90-481-9485-8_28.

Elliott, Richard. "Delivering on the Pledge: Global Access to Medicines, WTO Rules, and Reforming Canada's Law on Compulsory Licensing for Export.” McGill International Journal of Sustainable Development Law and Policy 3 (2007): 23-67.

European Commission. (EC 2000a). Regulation 141/2000, 2000 O.J. (L18) 1-5 (EC) of the European Parliament and of the Council of 16 December 1999 on Orphan Medicinal Products.

European Commission. (EC 2000b). Regulation 847/2000, 2000 O.J. (L103) 5-8 (EC). European Patent Convention, 5 October 1973, 1065 U.N.T.S. 199, art. 63(2)(b).

Fernandez, Conrad V. "Our Moral Obligations in Caring for Patients with Orphan Cancers." CMAJ: Canadian Medical Association Journal 176, no. 3 (January 30, 2007): 297. doi:10.1503/cmaj.061623. 
Flood, Colleen M. and Patrick Dyke. "The Data Divide: Managing the Misalignment in Canada's Evidentiary Requirements for Drug Regulation and Funding.” UBC Law Review 45, no. 2 (2012): 283-328.

Food and Drug Administration. (FDA 2013). "Designating an Orphan Product: Drugs and Biologics - Common EMEA/FDA Application for Orphan Medicinal Product Designation" WebContent. Accessed January 23, 2013. http://www.fda.gov/ForIndustry/DevelopingProductsforRareDiseasesConditions/Howtoa pplyforOrphanProductDesignation/ucm124795.htm.

Food and Drug Administration. (FDA) (2012). Research, Center for Drug Evaluation and. "Biosimilars" WebContent. Accessed December 31, 2012. http://www.fda.gov/Drugs/DevelopmentApprovalProcess/HowDrugsareDevelopedandAp proved/ApprovalApplications/TherapeuticBiologicApplications/Biosimilars/default.htm.

Food and Drug Administration. (FDA) (2011). Orphan Drug Regulations: Proposed Rules, 76 Fed. Reg. 64868—64879.

Food and Drug Administration. (FDA) (1986). Policy of Eligibility of Drugs for Orphan Designation, 51 Fed. Reg. 4505.

Food and Drug Regulations (Canada 1985). C.R.C., c. 870, C.08.004.1. 
Frost and Sullivan. (2010). "Frost \& Sullivan: Orphan Drugs to Create Paradigm Shift in the Pharmaceutical Industry!” Accessed January 23, 2013. http://www.frost.com/prod/servlet/press-release.pag?docid=197715735

Galloway. Gloria. (2012). “Tories Block Bid to Make Cheaper Medicines for Poor Nations.” The Globe and Mail. Accessed December 29, 2012. http://www.theglobeandmail.com/news/politics/tories-block-bid-to-make-cheapermedicines-for-poor-nations/article5759286/.

Gericke, C. A., A. Riesberg, and R. Busse. "Ethical Issues in Funding Orphan Drug Research and Development." Journal of Medical Ethics 31, no. 3 (March 1, 2005): 164 168. doi:10.1136/jme.2003.007138.

Global Genes Project. (2012). Who We Are. http://globalgenes.org/who-we-are-2/.

Grootendorst, Paul, Aidan Hollis, David K Levine, Thomas Pogge, and Aled M Edwards. "New Approaches to Rewarding Pharmaceutical Innovation." CMAJ: Canadian Medical Association Journal $=$ Journal De l'Association Medicale Canadienne 183, no. 6 (April 5, 2011): 681-685. doi:10.1503/cmaj.100375.

Gupta, Samir. "Rare Diseases: Canada's 'research Orphans'." Open Medicine 6, no. 1 (February 28, 2012): 24-27. 
Haffner, Marlene E. “Adopting Orphan Drugs--two Dozen Years of Treating Rare

Diseases." The New England Journal of Medicine 354, no. 5 (February 2, 2006): 445447. doi:10.1056/NEJMp058317.

Haffner, Marlene E, Josep Torrent-Farnell, and Paul D Maher. "Does Orphan Drug Legislation Really Answer the Needs of Patients?" The Lancet 371, no. 9629 (June 2008): 2041-2044. doi:10.1016/S0140-6736(08)60873-9.

Harper, Andrew R., and Eric J. Topol. "Pharmacogenomics in Clinical Practice and Drug Development.” Nature Biotechnology 30, no. 11 (2012): 1117-1124. doi:10.1038/nbt.2424.

Health Canada. (2012a) “An Orphan Drug Framework for Canada - Health Canada News Release 2012-10-03” Media release, August 3, 2012. http://www.hc-sc.gc.ca/ahcasc/media/nr-cp/_2012/2012-147a-eng.php.

Health Canada. (2012b). "Federal Government Takes Action to Help Canadians with Rare Diseases - Health Canada News Release 2012-10-03” Media release, October 3, 2012. http://www.hc-sc.gc.ca/ahc-asc/media/nr-cp/_2012/2012-147-eng.php. 
Health Canada. (1997a). "Policy Issues: Orphan Drug Policy" Correspondence, January 16, 1997. http://www.hc-sc.gc.ca/dhp-mps/prodpharma/applic-demande/pol/orph_poleng.php.

Health Canada. (1997b). "Guidance for Industry: Good Clinical Practice: Consolidated Guideline: ICH Topic E6" Notice, September 19, 1997. http://www.hc-sc.gc.ca/dhpmps/prodpharma/applic-demande/guide-ld/ich/efficac/e6-eng.php.

ICH. (1996). "Guideline for Good Clinical Practice." European Union, Japan and USA (1996). http://www.cinme.com.ar/english/lecturas/ICH_E6_Guias_BPC.pdf.

Heemstra, Harald E, Thijs J Giezen, Aukje K Mantel-Teeuwisse, Remco L A de Vrueh, and Hubert G M Leufkens. "Safety-related Regulatory Actions for Orphan Drugs in the US and EU: a Cohort Study." Drug Safety: An International Journal of Medical Toxicology and Drug Experience 33, no. 2 (February 1, 2010): 127-137. doi:10.2165/11319870-000000000-00000.

Heemstra, Harald E., Sonja van Weely, Hans A. Büller, Hubert G.M. Leufkens, and Remco L.A. de Vrueh. "Translation of Rare Disease Research into Orphan Drug Development: Disease Matters." Drug Discovery Today 14, no. 23-24 (December 2009): 1166-1173. doi:10.1016/j.drudis.2009.09.008. 
Hemphill, Thomas A. "Extraordinary Pricing of Orphan Drugs: Is It a Socially

Responsible Strategy for the U.S. Pharmaceutical Industry?" Journal of Business Ethics 94, no. 2 (June 1, 2010): 225-242. doi:10.1007/s10551-009-0259-x.

Herder, Matthew. "Unlocking Health Canada's Cache of Trade Secrets: Mandatory Disclosure of Clinical Trial Results." CMAJ: Canadian Medical Association Journal = Journal De l'Association Medicale Canadienne 184, no. 2 (February 7, 2012): 194-199. doi:10.1503/cmaj.110721.

Herder, Matthew. (2013). "Choice Patents." IDEA: The Intellectual Property Law Review 53, no. 1 (forthcoming 2013).

Herder, Matthew. "Patents \& the Progress of Personalized Medicine: Biomarkers Research as Lens." Annals of Health Law / Loyola University Chicago, School of Law, Institute for Health Law 18, no. 2 (2009): 187-229, 8 p. preceding i.

Hohl, Corinne M., Bohdan Nosyk, Lisa Kuramoto, Peter J. Zed, Jeffrey R. Brubacher, Riyad B. Abu-Laban, Samuel B. Sheps, and Boris Sobolev. "Outcomes of Emergency Department Patients Presenting With Adverse Drug Events." Annals of Emergency Medicine 58, no. 3 (September 2011): 270-279.e4.

doi:10.1016/j.annemergmed.2011.01.003. 
Hollis A. Drugs for rare diseases: paying for innovation. Health services restructuring in Canada: new evidence and new directions 2006;155.

Huyard, Caroline. "How Did Uncommon Disorders Become 'Rare Diseases'? History of a Boundary Object." Sociology of Health \& Illness 31, no. 4 (May 2009): 463-477. doi:10.1111/j.1467-9566.2008.01143.x.

Japan. Ministry of Health, Labour and Welfare. (2009). Overview of Orphan Drug / Medical Device Designation System. http://www.mhlw.go.jp/english/policy/healthmedical/pharmaceuticals/orphan_drug.html

Jayadev, Arjun, and Joseph Stiglitz. “Two Ideas To Increase Innovation And Reduce Pharmaceutical Costs And Prices." Health Affairs 28, no. 1 (January 1, 2009): w165w168. doi:10.1377/hlthaff.28.1.w165.

Kesselheim, Aaron S. “An Empirical Review of Major Legislation Affecting Drug Development: Past Experiences, Effects, and Unintended Consequences.” Milbank Quarterly 89, no. 3 (September 1, 2011): 450-502. doi:10.1111/j.14680009.2011.00636.x.

Kesselheim, Aaron S, Jessica A Myers, and Jerry Avorn. "Characteristics of Clinical Trials to Support Approval of Orphan Vs Nonorphan Drugs for Cancer." JAMA: The 
Journal of the American Medical Association 305, no. 22 (June 8, 2011): 2320-2326. doi:10.1001/jama.2011.769.

Kesselheim, Aaron S, and Daniel H Solomon. "Incentives for Drug Development--the Curious Case of Colchicine." The New England Journal of Medicine 362, no. 22 (June 3, 2010): 2045-2047. doi:10.1056/NEJMp1003126.

Kirby, Tony. "Australia Makes up for Lost Time on Rare Diseases.” The Lancet 379, no. 9827 (May 2012): 1689-1690. doi:10.1016/S0140-6736(12)60702-8.

Lang, T., A. V. S. Hill, H. McShane, R. Shah, A. Towse, C. Pritchard, and M. Garau. "New Tb Vaccine Granted Orphan Drug Status." BMJ: British Medical Journal 331, no. 7530 (December 17, 2005): 1476.

Law, Michael R., Yuko Kawasumi, and Steven G. Morgan. "Despite Law, Fewer Than One In Eight Completed Studies Of Drugs And Biologics Are Reported On Time On ClinicalTrials.gov." Health Affairs 30, no. 12 (December 1, 2011): 2338 -2345. doi:10.1377/hlthaff.2011.0172.

Lehoux, Pascale, Bryn Williams-Jones, Fiona Miller, David Urbach, and Stephanie Tailliez. "What Leads to Better Health Care Innovation? Arguments for an Integrated Policy-oriented Research Agenda." Journal of Health Services Research \& Policy 13, no. 4 (October 1, 2008): 251-254. doi:10.1258/jhsrp.2008.007173. 
Lexchin, Joel. "New Drugs and Safety: What Happened to New Active Substances Approved in Canada Between 1995 and 2010?" Archives of Internal Medicine (October 8, 2012): 1-2. doi:10.1001/archinternmed.2012.4444.

Light, D. W., and J. R. Lexchin. "Pharmaceutical Research and Development: What Do We Get for All That Money?” BMJ 345, no. aug07 1 (August 7, 2012): e4348-e4348. doi:10.1136/bmj.e4348.

Light, D. W., and R. Warburton. "Demythologizing the High Costs of Pharmaceutical Research.” Biosocieties 6, no. 1 (2011): 34-50.

Loughnot, D. "Potential Interactions of the Orphan Drug Act and Pharmacogenomics: a Flood of Orphan Drugs and Abuses." Am. JL \& Med. 31 (2005): 365.

Maher, Paul D., and Marlene Haffner. "Orphan Drug Designation and Pharmacogenomics: Options and Opportunities." BioDrugs 20, no. 2 (March 2006): 71.

McCabe, Christopher, Karl Claxton, and Aki Tsuchiya. "Orphan Drugs And The Nhs: Should We Value Rarity?” BMJ: British Medical Journal 331, no. 7523 (October 29, 2005): 1016-1019. 
Meekings, Kiran N, Cory S M Williams, and John E Arrowsmith. "Orphan Drug

Development: An Economically Viable Strategy for Biopharma R\&D.” Drug Discovery

Today 17, no. 13-14 (July 2012): 660-664. doi:10.1016/j.drudis.2012.02.005.

Menon, Devidas, and Tania Stafinski. "Engaging the Public in Priority-setting for Health Technology Assessment: Findings from a Citizens' Jury.” Health Expectations: An International Journal of Public Participation in Health Care and Health Policy 11, no. 3 (September 2008): 282-293. doi:10.1111/j.1369-7625.2008.00501.x.

__. "Role of Patient and Public Participation in Health Technology Assessment and Coverage Decisions." Expert Review of Pharmacoeconomics \& Outcomes Research 11, no. 1 (February 2011): 75-89. doi:10.1586/erp.10.82.

Menon, Devidas, Tania Stafinski, and Douglas Martin. "Priority-setting for Healthcare: Who, How, and Is It Fair?" Health Policy (Amsterdam, Netherlands) 84, no. 2-3 (December 2007): 220-233. doi:10.1016/j.healthpol.2007.05.009.

Michaux, Genevieve. "EU Orphan Regulation - Ten Years of Application." Food and Drug Law Journal 65, (2010): 639-669.

Milne, Christopher-Paul, and Joyce Tait. "Evolution Along the Government Governance Continuum: FDA's Orphan Products and Fast Track Programs as Exemplars 
of What Works for Innovation and Regulation." Food and Drug Law Journal 64 (2009): 733.

Mitsumoto, Jun, E Ray Dorsey, Christopher A Beck, Karl Kieburtz, and Robert C Griggs. "Pivotal Studies of Orphan Drugs Approved for Neurological Diseases." Annals of Neurology 66, no. 2 (August 2009): 184-190. doi:10.1002/ana.21676.

Morgan, Steven G, Kenneth L Bassett, James M Wright, Robert G Evans, Morris L Barer, Patricia A Caetano, and Charlyn D Black. “'Breakthrough’ Drugs and Growth in Expenditure on Prescription Drugs in Canada." BMJ (Clinical Research Ed.) 331, no. 7520 (October 8, 2005): 815-816. doi:10.1136/bmj.38582.703866.AE.

Narukawa, M. "Japanese Approach to Orphan Products." The European Regulation on Orphan Medicinal Products (2001): 41.

Network, The Cancer Genome Atlas. "Comprehensive Molecular Portraits of Human Breast Tumours.” Nature 490, no. 7418 (October 4, 2012): 61-70. doi:10.1038/nature11412.

Orphan Drug Act of 1983, Pub. L. No. 97-414, 96 Stat. 2049.

Orphan Drug Regulations, 57 Fed. Reg. 62,076, 62,081 (Dec. 29, 1992). 
Panju, Abbas H, and Chaim M Bell. "Policy Alternatives for Treatments for Rare

Diseases." Canadian Medical Association Journal 182, no. 17 (November 23, 2010): E787-E792. doi:10.1503/cmaj.081429.

Peterson, Matt, Aidan Hollis, and Thomas Pogge. "A Critique in Need of Critique." Public Health Ethics 3, no. 2 (July 1, 2010): 178-185. doi:10.1093/phe/php037.

Pinxten, Wim, Yvonne Denier, Marc Dooms, Jean-Jacques Cassiman, and Kris Dierickx. "A Fair Share for the Orphans: Ethical Guidelines for a Fair Distribution of Resources Within the Bounds of the 10-Year-Old European Orphan Drug Regulation.” Journal of Medical Ethics 38, no. 3 (March 1, 2012): 148-153. doi:10.1136/medethics-2011100094.

Pogge, Thomas W. "HUMAN RIGHTS AND GLOBAL HEALTH: A RESEARCH PROGRAM.” Metaphilosophy 36, no. 1-2 (2005): 182-209. doi:10.1111/j.14679973.2005.00362.x.

Rai, Arti K. "PHARMACOGENETIC INTERVENTIONS, ORPHAN DRUGS, AND DISTRIBUTIVE JUSTICE: THE ROLE OF COST-BENEFIT ANALYSIS." Social Philosophy and Policy 19, no. 02 (2002): 246-270. doi:10.1017.S0265052502192107. 
Reinecke, Martin, Kathrin Rommel, and Jörg Schmidtke. "Funding of Rare Disease Research in Germany: a Pilot Study.” Journal of Community Genetics 2, no. 2 (June 2011): 101-105. doi:10.1007/s12687-011-0045-1.

Rinaldi, Andrea. "Adopting an Orphan." EMBO Reports 6, no. 6 (June 2005): 507-510. doi:10.1038/sj.embor.7400450.

Sekeres, Melanie, Jennifer L. Gold, An-Wen Chan, Joel Lexchin, David Moher, Marleen L. P. Van Laethem, James Maskalyk, Lorraine Ferris, Nathan Taback, and Paula A. Rochon. "Poor Reporting of Scientific Leadership Information in Clinical Trial Registers.” PLoS ONE 3, no. 2 (February 20, 2008): e1610. doi:10.1371/journal.pone. 0001610 .

Seoane-Vazquez, Enrique, Rosa Rodriguez-Monguio, Sheryl Szeinbach, and Jay Visaria. "Incentives for Orphan Drug Research and Development in the United States." Orphanet Journal of Rare Diseases 3, no. 1 (December 16, 2008): 33. doi:10.1186/1750-1172-333.

Sharma, Aarti, Abraham Jacob, Manas Tandon, and Dushyant Kumar. "Orphan Drug: Development Trends and Strategies." Journal of Pharmacy and Bioallied Sciences 2, no. 4 (2010): 290-299. doi:10.4103/0975-7406.72128. 
Silversides, Ann. "Federal Committee to Review Appointment of Pfizer Vice-president to CIHR Governing Council.” CMAJ : Canadian Medical Association Journal 182, no. 1 (January 12, 2010): E33-E34. doi:10.1503/cmaj.109-3113.

Simoens, Steven. "Pricing and Reimbursement of Orphan Drugs: The Need for More Transparency." Orphanet Journal of Rare Diseases 6 (2011): 42. doi:10.1186/1750-1172$6-42$.

Spilker, Bert. (1986). "The development of orphan drugs: an industry perspective." In Scheinberg, I. Herbert and J.M. Walshe (eds.). Orphan Diseases and Orphan Drugs. Manchester University Press, 1986: 119-134.

Stafinski, Tania, Christopher J McCabe, and Devidas Menon. "Funding the Unfundable: Mechanisms for Managing Uncertainty in Decisions on the Introduction of New and Innovative Technologies into Healthcare Systems." PharmacoEconomics 28, no. 2 (2010): 113-142. doi:10.2165/11530820-000000000-00000.

Stallings, Sarah C, Dan Huse, Stan N Finkelstein, William H Crown, Whitney P Witt, Jon Maguire, Arthur J Hiller, Anthony J Sinskey, and Geoffrey S Ginsburg. "A Framework to Evaluate the Economic Impact of Pharmacogenomics.” Pharmacogenomics 7, no. 6 (September 2006): 853-862. doi:10.2217/14622416.7.6.853. 
Standing Senate Committee on Social Affairs, Science and Technology. (2012).

Canada's Clinical Trial Infrastructure: A Prescription for Improved Access to New Medicines. November 2012. http://www.parl.gc.ca/Content/SEN/Committee/411/SOCI/DPK/01nov12/home-e.htm

Standing Senate Committee on Social Affairs, Science and Technology. (2013).

Prescription Pharmaceuticals in Canada: Post-Approval Monitoring of Safety and Effectiveness. March 2013.

http://parl.gc.ca/Content/SEN/Committee/411/SOCI/rep/rep20mar13-e.pdf

Tansey, Katherine E., Michel Guipponi, Nader Perroud, Guido Bondolfi, Enrico

Domenici, David Evans, Stephanie K. Hall, et al. "Genetic Predictors of Response to Serotonergic and Noradrenergic Antidepressants in Major Depressive Disorder: A Genome-Wide Analysis of Individual-Level Data and a Meta-Analysis.” PLoS Med 9, no. 10 (October 16, 2012): e1001326. doi:10.1371/journal.pmed.1001326.

Thamer, M, N Brennan, and R Semansky. "A Cross-national Comparison of Orphan Drug Policies: Implications for the U.S. Orphan Drug Act." Journal of Health Politics, Policy and Law 23, no. 2 (April 1998): 265-290.

(TRIPS). WTO Agreement on Trade-Related Aspects of Intellectual Property Rights, 15 April 1994, 33 I.L.M. 1197. 
Trotta, Francesco, Hubert G.M. Leufkens, Jan H.M. Schellens, Richard Laing, and Giovanni Tafuri. "Evaluation of Oncology Drugs at the European Medicines Agency and US Food and Drug Administration: When Differences Have an Impact on Clinical Practice." Journal of Clinical Oncology (May 2, 2011). doi:10.1200/JCO.2010.34.1248.

Trouiller, Patrice, Els Torreele, Piero Olliaro, Nick White, Susan Foster, Dyann Wirth, and Bernard Pécoul. "Drugs for Neglected Diseases: a Failure of the Market and a Public Health Failure?" Tropical Medicine \& International Health 6, no. 11 (2001): 945-951. doi:10.1046/j.1365-3156.2001.00803.x.

Tyers, Mike, Eric Brown, David W Andrews, John J M Bergeron, Charles Boone, Roderick Bremner, Howard A Bussey, et al. "Problems with Co-funding in Canada." Science (New York, N.Y.) 308, no. 5730 (June 24, 2005): 1867. doi:10.1126/science.308.5730.1867b.

Valverde, Ana M., Shelby D. Reed, and Kevin A. Schulman. "Proposed 'Grant-AndAccess' Program With Price Caps Could Stimulate Development Of Drugs For Very Rare Diseases." Health Affairs 31, no. 11 (November 1, 2012): 2528-2535. doi:10.1377/hlthaff.2012.0235.

Vera-Badillo, F E, R Shapiro, A Ocana, E Amir, and I F Tannock. "Bias in Reporting of End Points of Efficacy and Toxicity in Randomized, Clinical Trials for Women with 
Breast Cancer." Annals of Oncology: Official Journal of the European Society for Medical Oncology / ESMO (January 9, 2013). doi:10.1093/annonc/mds636.

Viergever, Roderik F, and Davina Ghersi. “The Quality of Registration of Clinical Trials." PloS One 6, no. 2 (2011): e14701. doi:10.1371/journal.pone.0014701.

Warren, Kenneth S. (1986). "The great neglected diseases of mankind, or All the world's an orphanage." In Scheinberg, I. Herbert and J.M. Walshe (eds.). Orphan Diseases and Orphan Drugs. Manchester University Press, 1986: 169—176.

Waxman, Henry A. (1986). "The history and development of the Orphan Drug Act." In Scheinberg, I. Herbert and J.M. Walshe (eds.). Orphan Diseases and Orphan Drugs. Manchester University Press, 1986: 135-145.

Wellman-Labadie, Olivier, and Youwen Zhou. "The US Orphan Drug Act: Rare Disease Research Stimulator or Commercial Opportunity?" Health Policy 95, no. 2-3 (May 2010): 216-228. doi:10.1016/j.healthpol.2009.12.001.

Winquist, Eric, Chaim M Bell, Joe T R Clarke, Gerald Evans, Janet Martin, Mona Sabharwal, Anita Gadhok, Helen Stevenson, and Doug Coyle. "An Evaluation Framework for Funding Drugs for Rare Diseases." Value in Health: The Journal of the International Society for Pharmacoeconomics and Outcomes Research 15, no. 6 (October 2012): 982-986. doi:10.1016/j.jval.2012.06.009. 
Yin, Wesley. "Market Incentives and Pharmaceutical Innovation." Journal of Health

Economics 27, no. 4 (July 2008): 1060-1077. doi:10.1016/j.jhealeco.2008.01.002.

Yin, Wesley. "R\&D Policy, Agency Costs and Innovation in Personalized Medicine." Journal of Health Economics 28, no. 5 (September 2009): 950-962.

doi:10.1016/j.jhealeco.2009.06.011. 